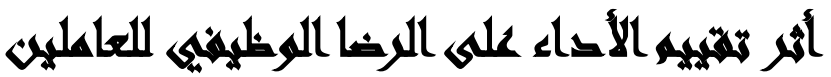

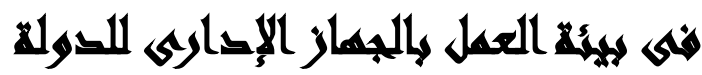

\section{[10]}

طارق محمد عبد العزيز حمزة (')- نادر ألبير فانوس(ץ)- محمود أحمد محمود أمين(†)

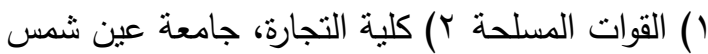

\section{المستخلص}

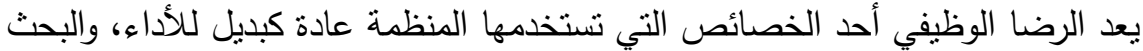

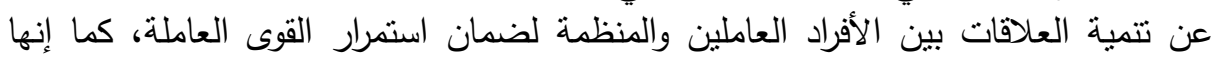

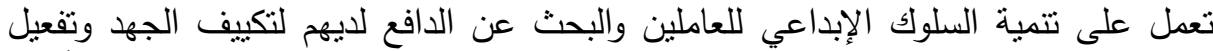

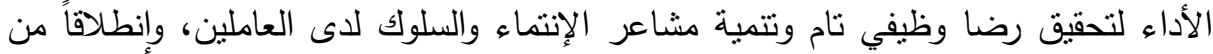

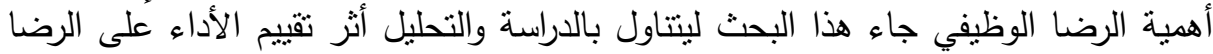

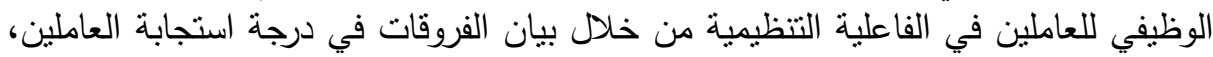

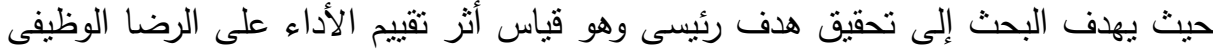

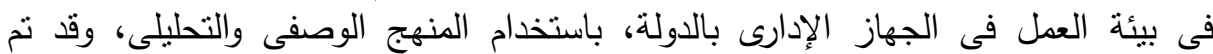

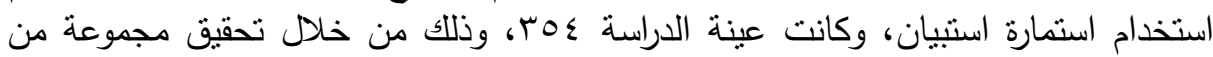

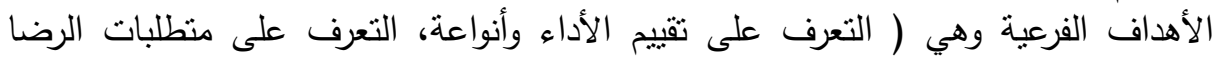

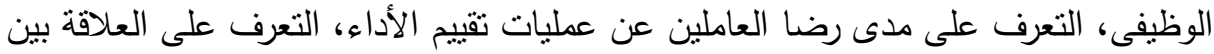

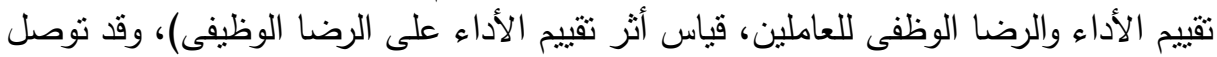

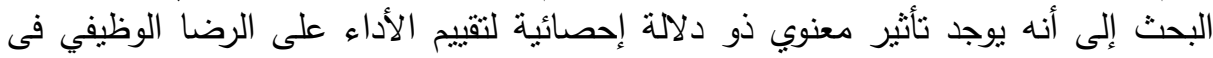

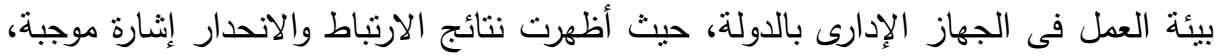

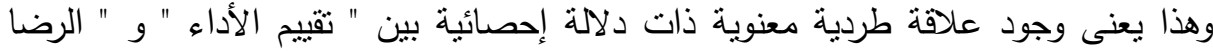

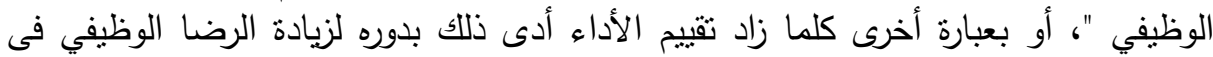

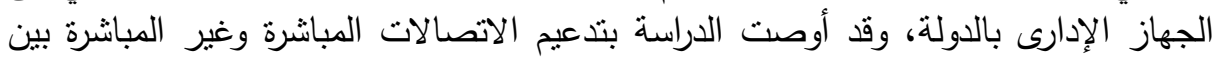

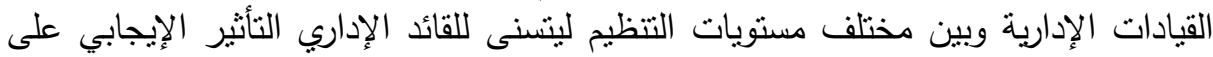

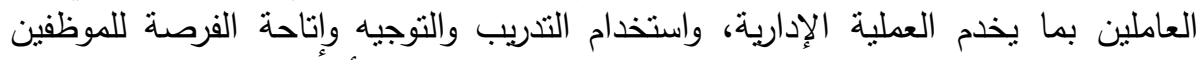

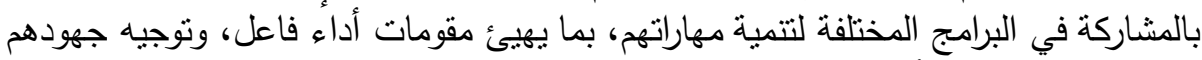
لتتعكس على مستوى أدائهم. الكلمات المفتاحية: ( الرضا الوظيفى - تقييم الأداء - الجهاز الإدارى للدولة )

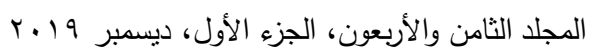




\section{xasadl}

مـع بداية القرن العشرين بدأت تلوح في الأفق بوادر موضوع الرضـا الوظيفي للعاملين

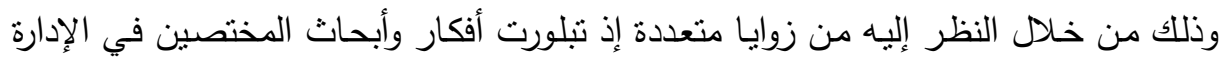
والسلوك الإنساني ذات العلاقة بموضوع الرضا الوظيفي والفاعلية التنظيمية من خلال الاهنمام

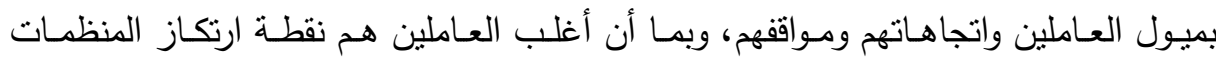

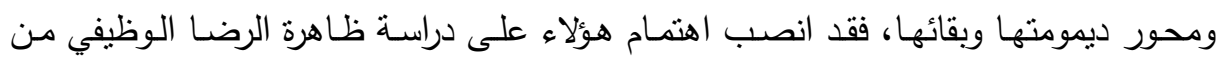
جوانب متعددة آخذين فى الاعتبار أثزها على الفاعلية التظظيمية.

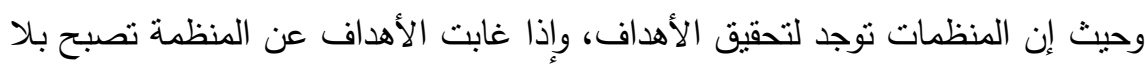

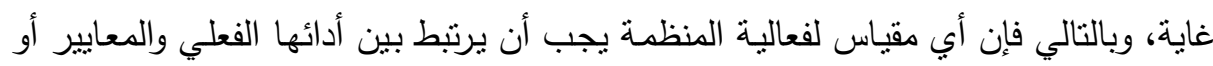

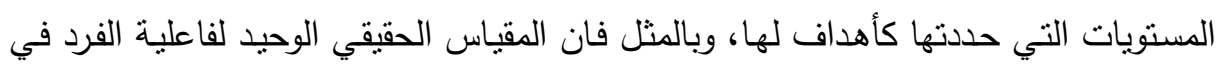
وظيفته هو مستوى أدائه، وفي حالة غياب مقاييس واضحة للأداء نستخدم بعض المنظمات

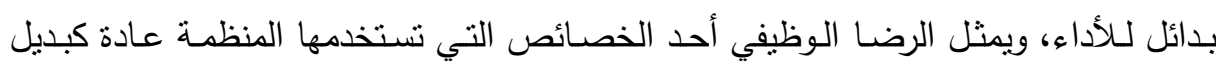

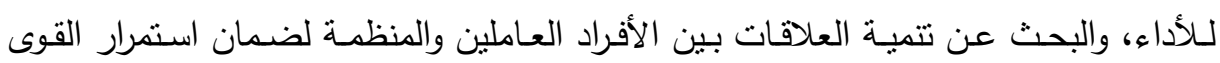

ولا شـك أن دراسـة المدير للرضـا الوظيفي عند موظفيه هي عملية تقويم شاملة تغطي جميع جوانب العمل وتتعرف الإدارة من خلالها على نفسها فتتكثف لها الإيجابيات والسلبيات

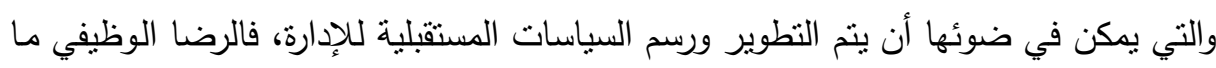

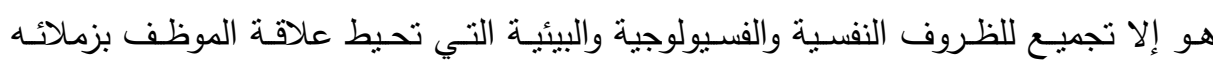
ورؤسائه وتتوافق مع شخصيته والتي تجعله يقول بصدق أنا سعيد بعملي، إذاً فالعملية تبادلية

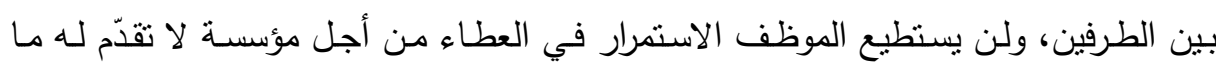

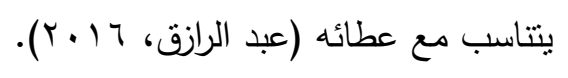
وانطلاقاً من أهمية الرضا الوظيفي جاء هذا البحث ليتتاول بالدراسة والتحليل أثر تقييم

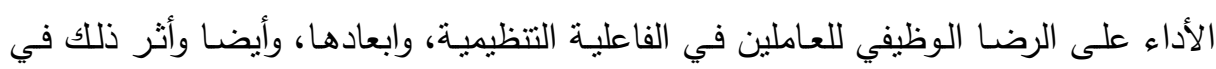
مداخل الفاعلية التتظيمية وابعادها من خلال بيان الفروقات في درجة استجابة العاملين. 


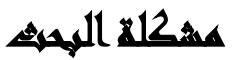

من خـلال قيام الباحث بإجراء دراسـة استطلاعية لمجموعة من العاملين بوزارة الزراعة بمختلف المستويات الإدارية على النحو التالى ( الإدارة العليا بنسبة ؟\%٪، إدارة وسطى بنسبة

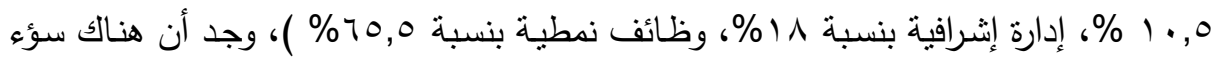

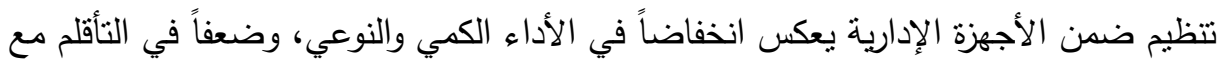
التغيرات المستمرة في البيئة الداخلية والخارجية.

\section{أسئلا الصوراسة}

\section{" ما مدى تأثير تقييم الأداء على الرضا الوظيفى فى بيئة العمل فى}

الجهاز الإدارى بالدولة"، مما يقودنا إلى مجموعة من التساؤلات الفرعية الهامة مثل:

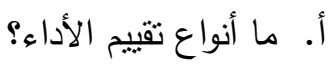

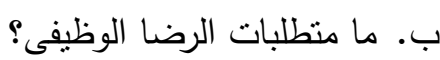

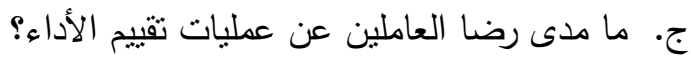

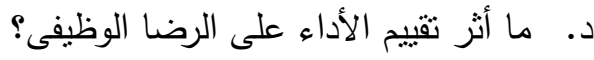

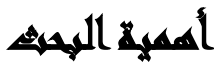

تعود أهمية البحث الى اهمية الرضا الوظيفي لدى العاملين فى الجهاز الإدارى للدولة،

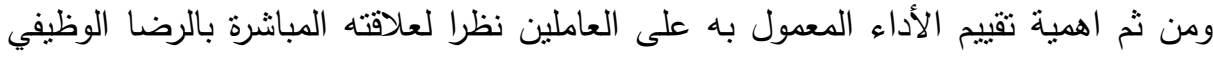

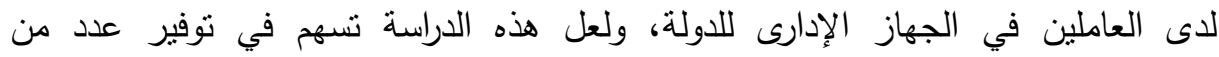
التوصيات والمقترحات لتفعيل نظم التقييم الإدارى ومن ثم رفع مستوى الرضا والولاء الوظيفي

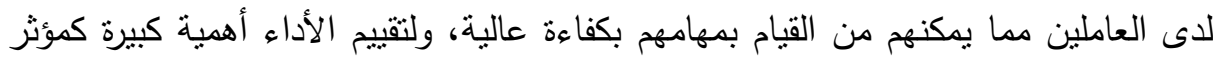
على الرضا الوظيفي لاى العاملين، لذا فإن هذه الدراسة ستتضمن معلومات عن الأداء من بهن حيث مفهومه وتقييمه وتحسينه. 


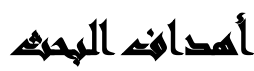

يسعى هذا البحث إلى تحقيق هدف رئيسى وهو قياس أثز تقييم الأداء على الرضـا

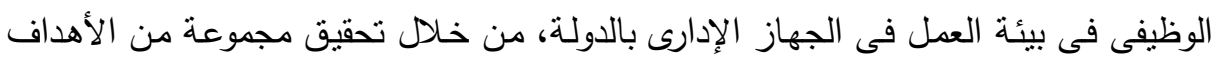

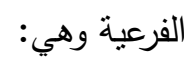

$$
\text { أ. التعرف على تقيبم الأداء وأنواعة . }
$$

ب. التعرف على منطلبات الرضا الوظيفى. ج. التعرف على مدى رضا العاملين عن عمليات تقييم الأداء. د. التعرف على العلاقة بين تقييم الأداء والرضا الوظفى للعاملين. هـ. قياس أثر تقييم الأداء على الرضا الوظيفى.

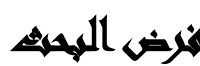

- لا يوجد تأثثر جوهرى ذو دلالة إحصائية لتقييم الأداء على الرضا الوظيفى فى بيئة العمل فى الجهاز الإدارى بالدولة.

\section{Aang}

$$
\begin{aligned}
& \text { الحدود المكانية: وزارة الزراعة } \\
& \text { الحدود الزمنية: } 9 \text { ب. }
\end{aligned}
$$

\section{هنهمج الميحه}

يعتمد هذا البحث على المنهج الوصفي التحليلي الذي يتضمن استخدام الأسلوب

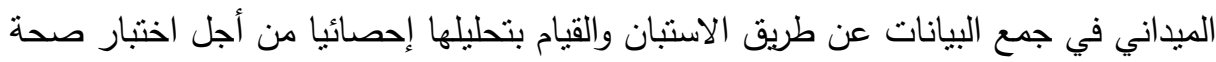
فروض الدراسة كما تعتمد على المسح المكتبي للاستفادة من الكتب والدوريات العلمية في بناء

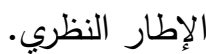




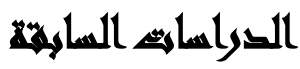

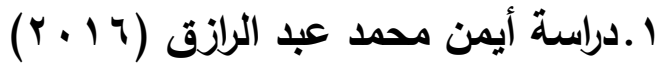

هدفت الدراسـة إلى تحقيق هدف رئيسى وهو قياس أثر الإصـلاح الإدارى على تتمية

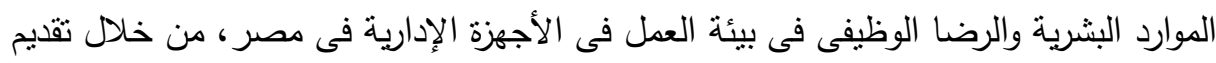

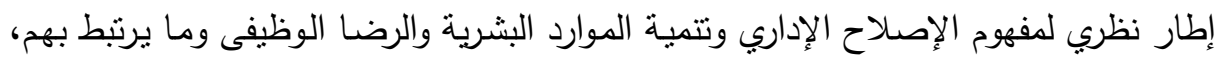

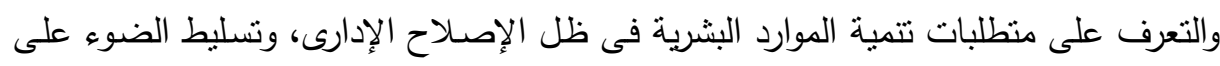
النظام الإداري وتتمية الموارد البشرية.

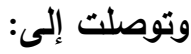

1-إن عمل الإصلاح داخل الأجهزة الإدارية من تطوير تتظيمى وإعادة هيكلة وتقييم للأداء

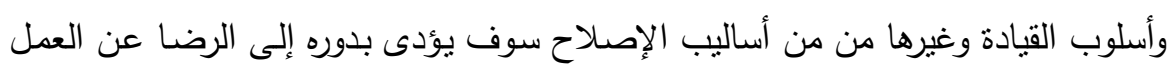

$$
\text { ورفع الروح المعنوية لهم مما يؤدى إلى الرضا الوظيفى. }
$$

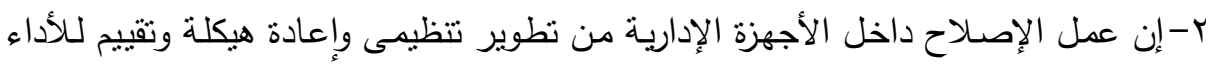

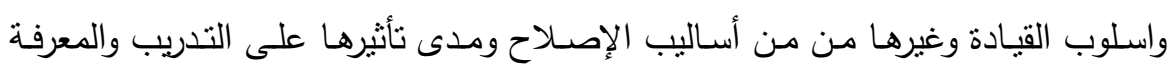

$$
\text { والتعلم التنظيمى، سوف يؤدى بدوره إلى تتمية الموارد البشرية. }
$$

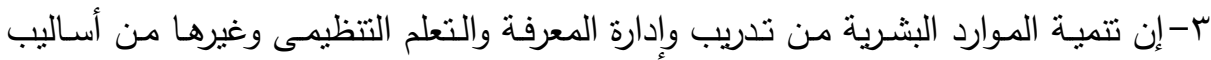

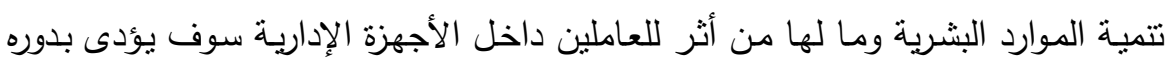

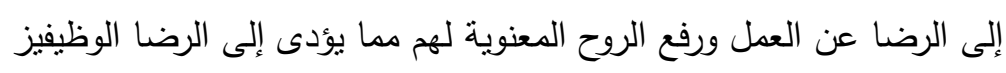

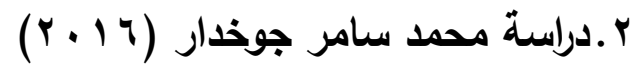

هـفت الاراسـة الى التعرف على السمات الأساسية للولاء التتظيمي لكافة الموظفين

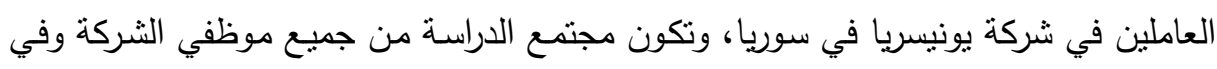

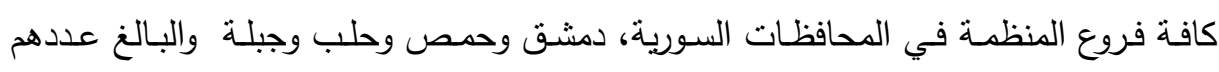

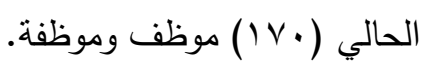

وتوصلت الى وجود انخفاض في المعنويات لدى العاملين في شركة يونسيريا وانهم دائماً

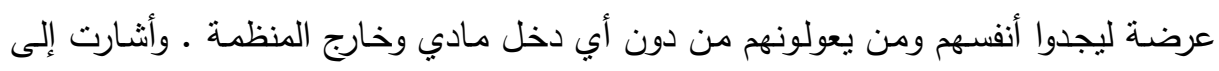


انخفاض الولاء للمنظمـة نتيجـة انخفاض مستوى الرضـا الوظيفي من حيث مـا يقدمونه ومـا

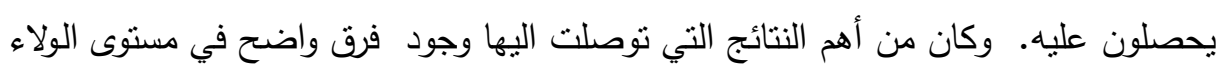

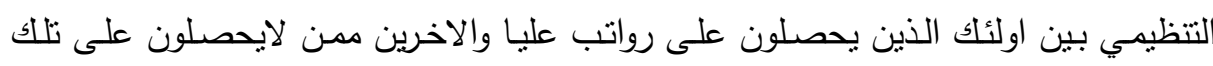
الرواتب .

\section{FOULD-WILLIAMS, JULIAN S. AND OTHERS (2014) ب. دراسة} هدفت هذه الدراسة إلى دراسة نأثير المنظمة ذات الصلة، والتزام العاملين العالى

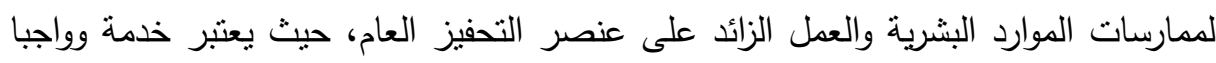
وطنيا لنتائج الموظف ( الرضا الوظيفي والالتزام العاطفي، والإقلاع عن النوايا ).

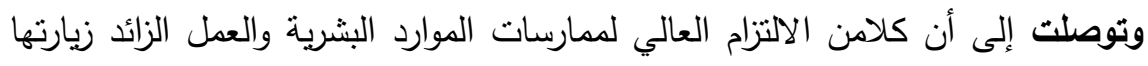

$$
\text { المباشر وغير المباشر يؤثر (عبر واجب مدني) على نتائج الموظف. المبن. }
$$

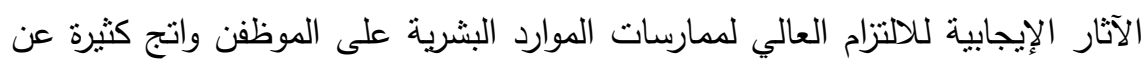

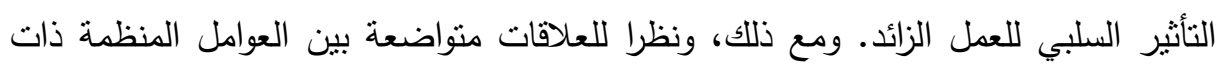
الصلة والعقلية المدنية، حيث يجب بذل جهود حازمة تركز ربما في المقام الأول على حملات توظيف واستبقاء بدلا من استراتيجيات التدريب والتتشئة الاجتماعية.

\section{Andreassi, Jeanine Karin,and others (2014) ـ دراسة}

هدفت إلى دراسة تأثنير ثقافة ممارسات الموارد البشرية عالية الأداء على الرضا الوظيفي

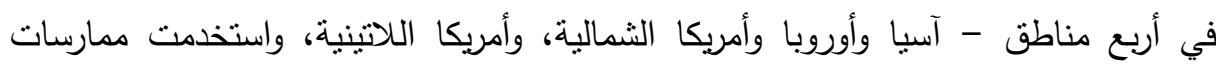

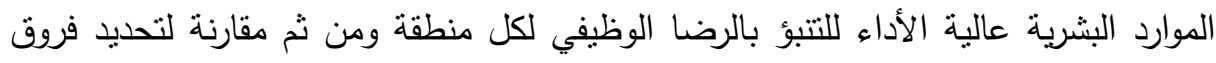

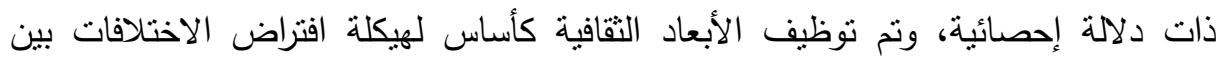
المناطق الثقافية.

وتوصلت إلى أن هناك علاقات كبيرة بين خصائص العمل والرضا الوظيفي في جميع مناطق العالم، مع شعور بالإنجاز عالميا والأكثر أهمية. على الرغم من أن الرضان الوضئ الوظيفي

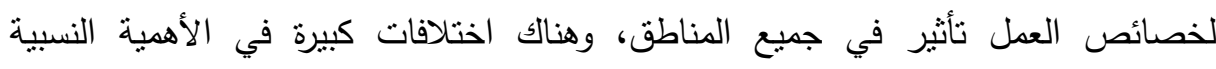
لخصائص العمل على الرضا الوظيفي، بما يتفق مع الأبعاد النقافية. 
ه • دراسـة: González Santa Cruz, Francisco - López-Guzmán, Tomás - Sánchez Cañizares, Sandra María (2014)

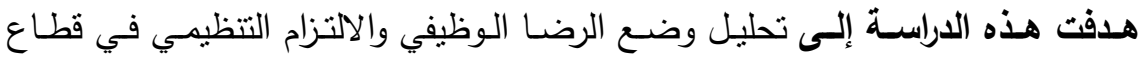
الضيافة في قرطبة (إسبانيا)، في محأولة لتحليل التأثثر المحتمل أو العلاقة بين تصنيف لرضيف التعاقدي والوقت التفاني في كل من يبني. وتوصلت إلى أن العمال تحت علاقات العمل الدائمـة لديها مستوى أعلى من الالتزام التنظيمي، ولكن ليس في حالة الرضا الوظيفي تعطى أكثر من الطابع العالمي الدوريه لها.

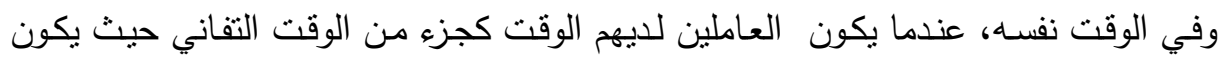
التزامهم أعلى، كما أنه يسمح للمصالحة أفضل بين العمل والحياة العائلية

צ. AlZalabani, Abdulmonem - Modi, Rajesh S. (2014) دراسة هدفت هذه الدراسـة إلى استكثاف تأثثر ممارسـة إدارة الموارد البشرية وينظر الدعم التنظيمي على الرضا الوظيفي في سياق المملكة العربية السعودية.

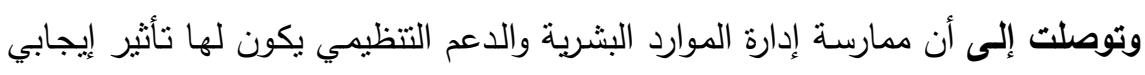

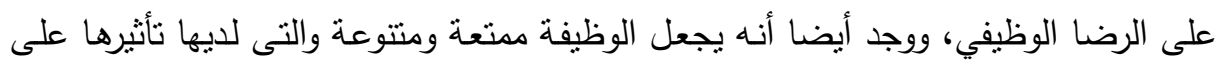

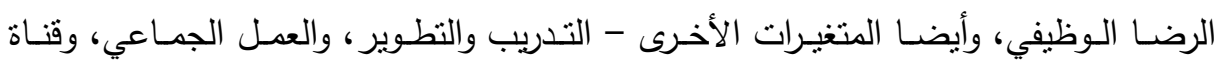

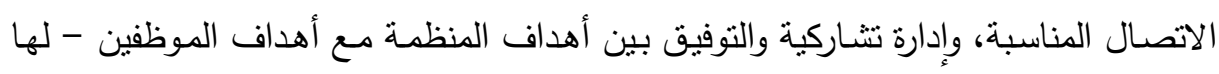
تأثثير كبير على الرضا الوظيفي.

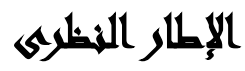

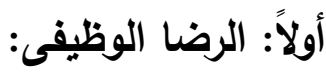

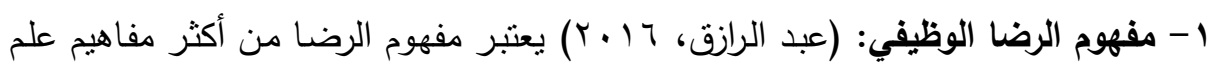

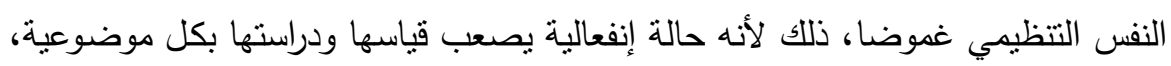
ولعل غموض هذا المفهوم هو الذي أدى إلى ظهور المئات من البحوث والدراسات حول هذا الموضوع، حيث تعددت واختلفت التعريفات التي حاولت تحديد مفهوم الرضا الوظيفي،

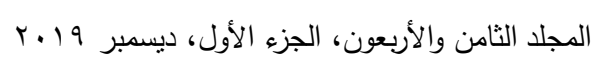


ويرجع التعدد والاختلاف إلى وجهات النظر المختلفة التي حاولت تحديد هذا المفهوم، وكان من أول التعاريف لمفهوم الرضا الوظيفي بصفة عامة ما قام بـه كل من (جينزبرغ)

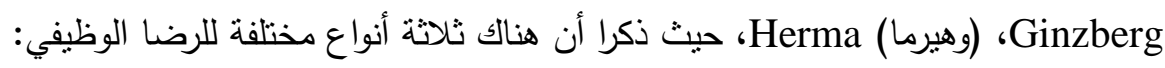
عوامل الرضـا الداخلية ومصدرها السعادة الوظيفية وإحساس الفرد وشعوره بما يحققه من مستويات اجتماعية للنجاح وتحقيقه لقدراته الثخصية فيما حققه من نجاح •

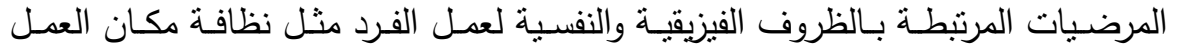

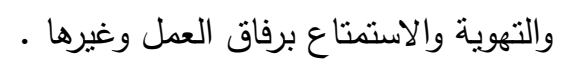
المرضيات الخارجية وهي المكافأت والأجور والعلاقات وليس المهم هو كم هذه المرضيات فحسب، وإنما هو علاقة هذا الكم بتوقعات الفرد باعتبارها وظيفة لقيمه وأهدافه.

\section{r ب بض التعاريف حول مصطلح الرضا عن العمل:}

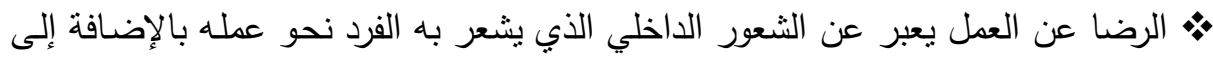

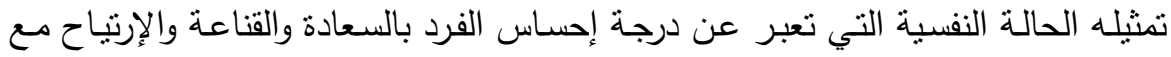

$$
\text { العمل نفسه وبيئة العمل وكذا المؤثرات الأخرى (عاشور ، }
$$

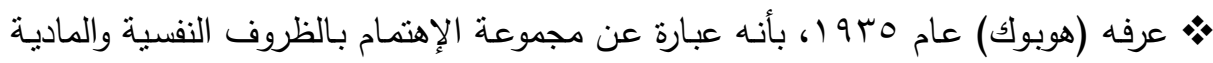

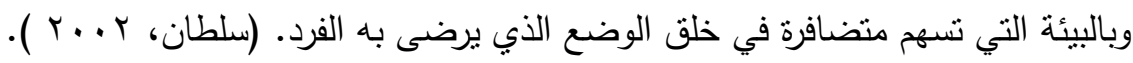

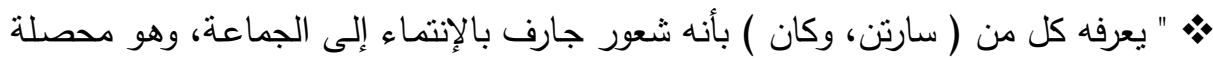

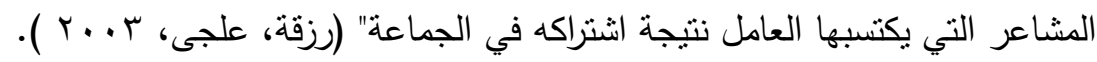

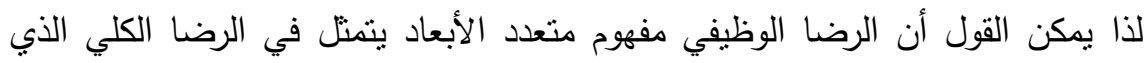

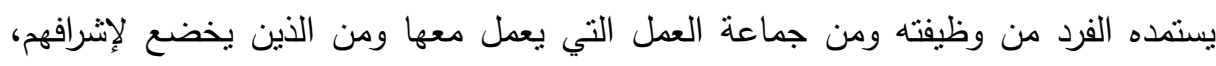
وكذللك من المنظمة والبيئة التي يعمل فيها، وباختصار فإن الرضا الوظيفي هو دالة لهنه لسعادة

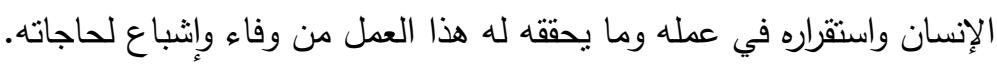

\section{r- طرائق قياس الرضا الوظيفي والعوامل المؤثرة في قياسها:}

إن قياس الرضا الوظيفي يهم كلا من علماء النفس والمدراء، فالكثير من القرارات الإدارية تفحص وتدرس حسب مدي نأثيرها علي الرضا الوظيفي، وعليه فقد كان نطوير فياس

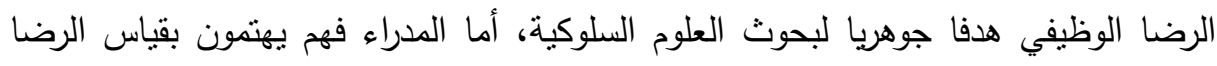


الوظيفي حيث يعتبرونه مؤشرا للكفاءة التنظيمية، وهناك بعض المؤسسات التي تقوم بمسوحات دورية لقياس الروح المعنوية وتستعمل نتائج هذه المسوحات في بناء قراراتها الإدارية وتطويرها، مقياس الرضا الوظيفي لايشبه قياس خط طول أو عرض مبني مثنا، وذلك لأن

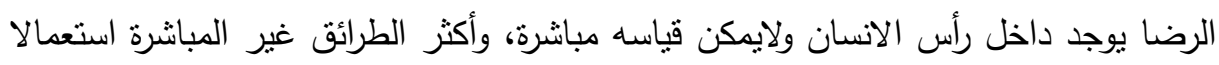

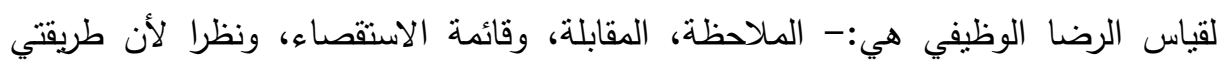
المقابلة والملاحظة تستلزمان وقتا كبيرا، فان الإستنيانات هي اكثر الطرائق استعمالا لتقييم

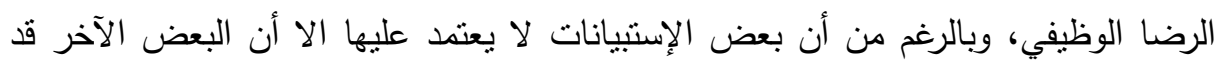

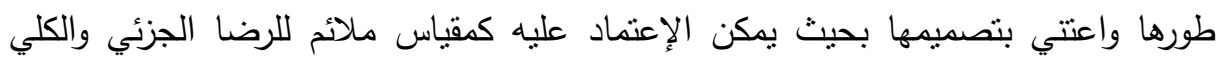

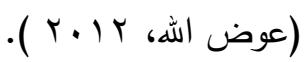
ع - أهمية الرضا الوظيفي:

معظم الأفراد يقضون جزءً كبيراً من حياتهم في العمل وبالتالي من الأهمية بمكان أن

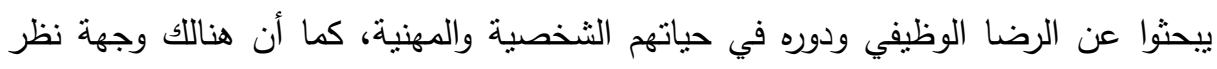
مفادها أن الرضا الوظيفي قد يؤدي إلي زيادة الإنتاجية ويترتب عليه الفائدة بالنسبة للمؤسسات

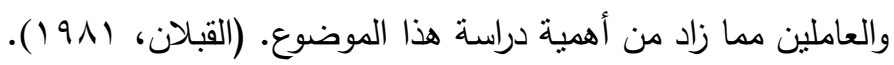

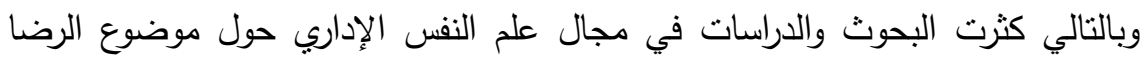

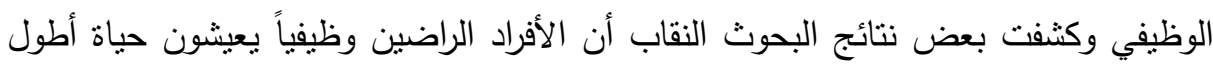

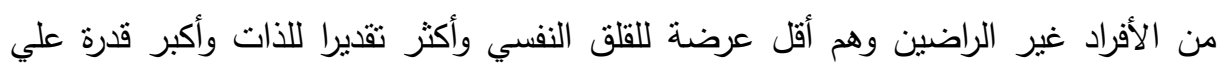
التكيف الإجتماعي ويؤكد البعض إلي أن هناك علاقة وثثقة بين الرضا عن الحياة والرفئ والرضيا

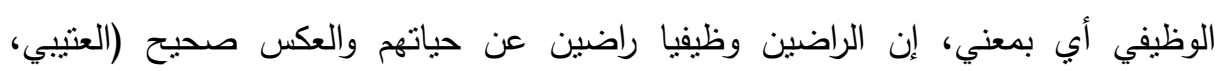

وقد ذكر "ليكرت" أنه يصعب تحقيق مستوي الإنتاج الرفيع علي مدي طويل من الزمن

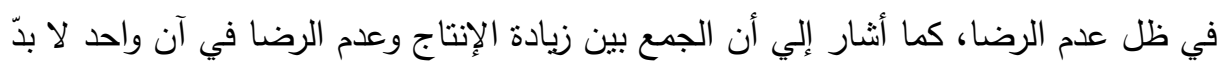

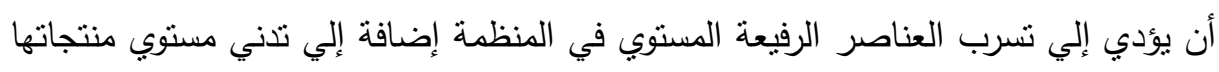

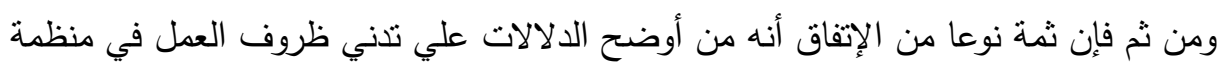

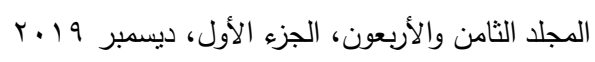


ما يتمتل في انخفاض مستوي الرضا لاي العاملين، والأسباب الداعية إلي الاهتمام بالرضا

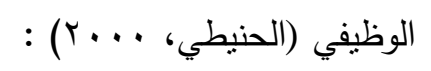
• إن ارتفاع درجة الرضا الوظيفي يؤدي إلي انخفاض نسبة غياب الموظفين

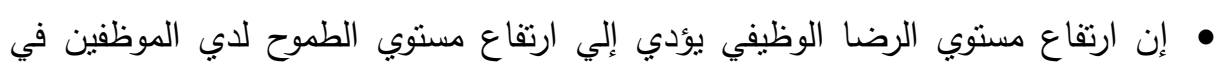
المؤسسات المختلفة.

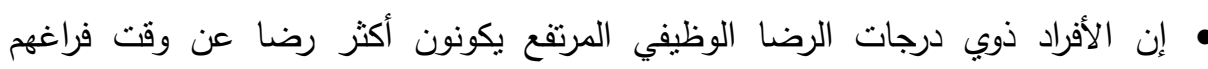

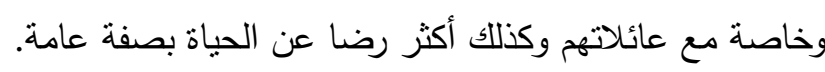

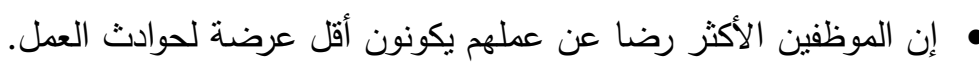

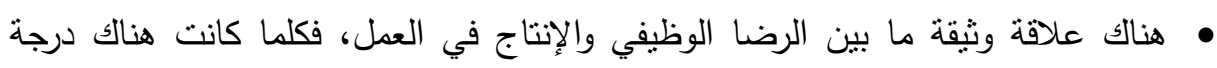
عالية من الرضا كلما زاد الإنتاج. وعموما يعتبر الرضا الوظيفي للموظفين من أهم مؤشرات الصحة والعافية للائرة ومدي الأني

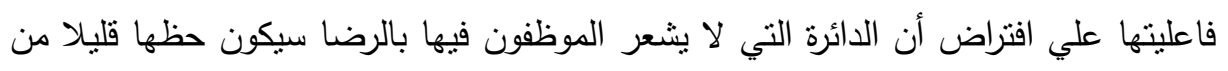

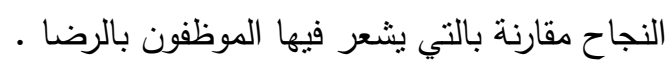

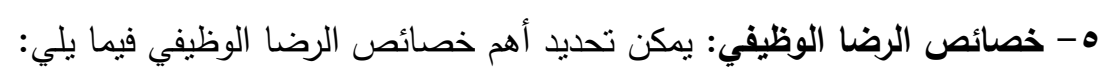

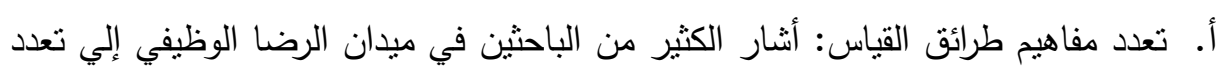

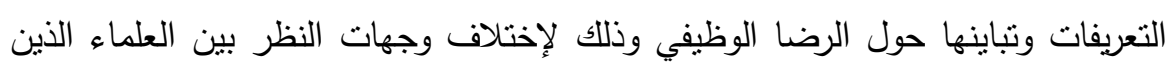
تختلف مداخلهم وأرضياتهم التي يققون عليها. ب. الرضا الوظيفي يتعلق بالعديد من الجوانب المتداخلة للسلوك الإنساني: نظراً لتعدد وتعقيد

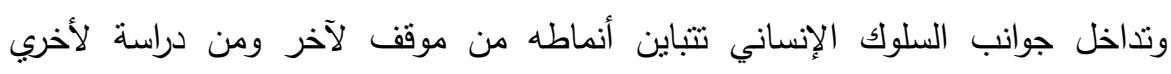

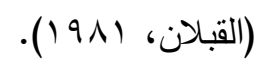

ج. الرضا الوظيفي حالة من القناعة والقبول: يتميز الرضا الوظيفي بأنه حالة من القناعة

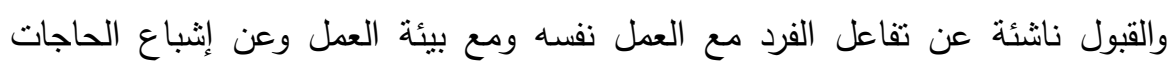

$$
\text { والرغبات والطموحات. }
$$


د. للرضا عن العمل ارتباط بسياق تتظيم العمل والنظام الإجتماعي: حيث يعد الرضا

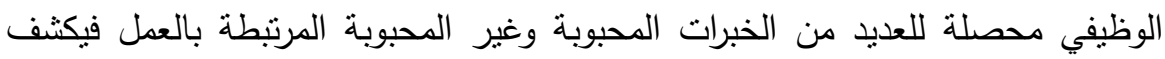

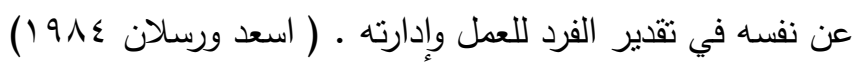
هـ. رضا الفرد عن عنصر معين ليس دليلا علي رضاه عن العناصر الأخري: إن رضا الفئ الفرد عن عنصر معين لا يمنل ذلك دليلا كافيا علي رضاه عن العناصر الأخري (شوقي، لهنياه

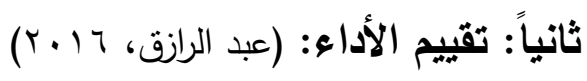

لكي نضـع الحافز المادي لكل موظف وفق عمله لابد أن نقيم الوظيفة التي يعمل بها

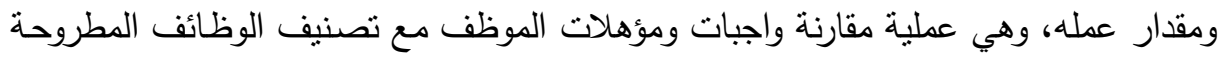
ووضع الثخص المناسب في المكان المناسب، أو هي " نظام، حيث ينت تجميع الوظائف في وهي الفئات التي تتوافق مع كمية من التدريب والمهارات والكفاءات والمعرفة أوالخبرة اللازمة للقيام بها "، حيث تعبر عن تحديد الوظائف الموجودة بالمنظمة على أساس أهميتها لتحقيق الأهداف لفه

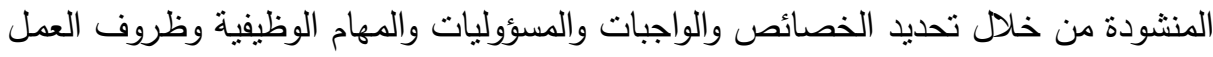
والمؤهلات اللازمة والنتائج المترتبة على ذلك. وحيث أن المنظمة تقوم على أداء موظفيها، واستمرارها يعتمد على قدرة موظفيها بالأداء

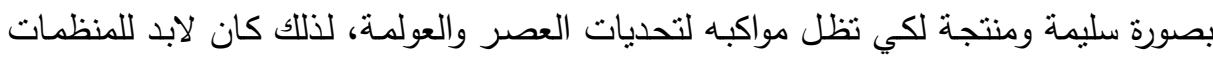
من قياس وتقييم مستويات العاملين لمعرفة مدى قدراتهم على الإنتاج والاستمرار في المنظمة، لونه

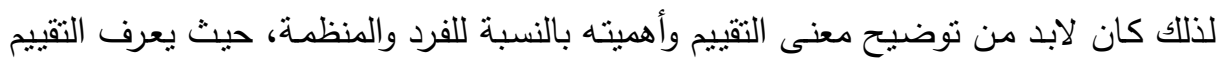

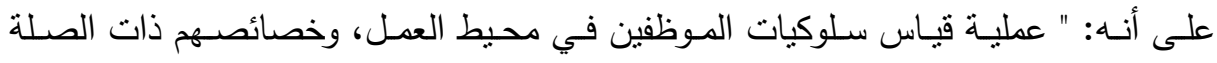

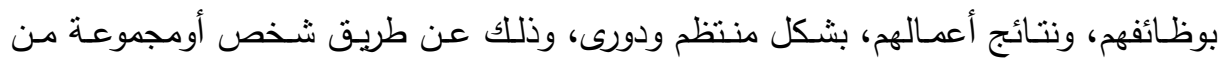

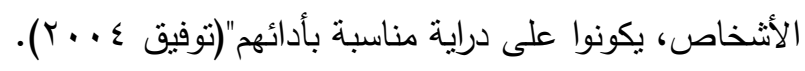




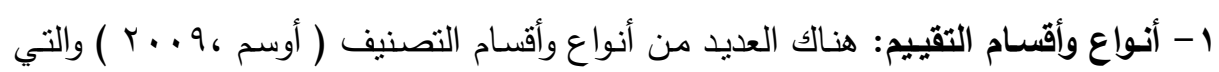
من أهمها:" الطريقة الأولى : الرئيس، المرؤوس، لجنة تقييم، زملاءالعمل.

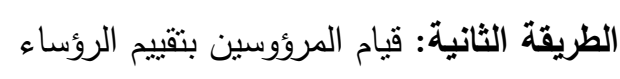
الطريقة الثالثة : تخص تقييم الزملاء. الطريقة الرابعة : وجود لجنة من الرؤساء

حيث تمنلك كل طريقة من هذه الطرق مجموعة من المميزات والعيوب بالإضافة إلى هلى لرؤياء

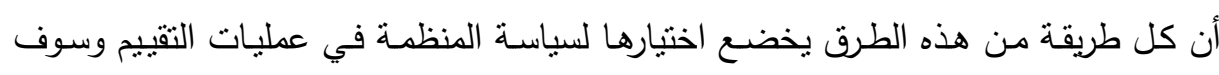

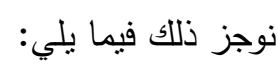
• تقيـيم الـرئيس والمشـرف: حيث يكون الأقرب للموظف ومراقب لأعمالـه بشكل يـومي

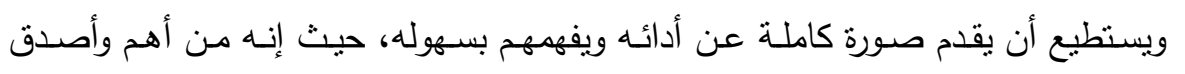

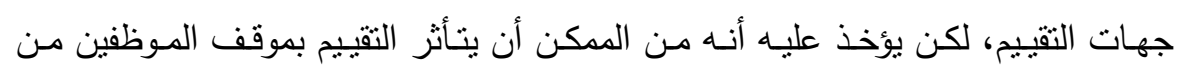
مشرفيهح - منات • تقييم رئيس المشرف المباشر: حيث يقوم الرئيس بمراجعة تقييم المشرف المباشر ، وأحيانا

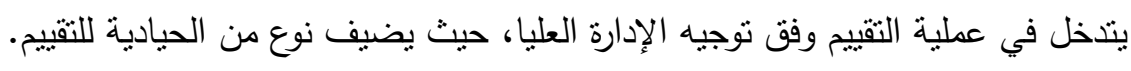

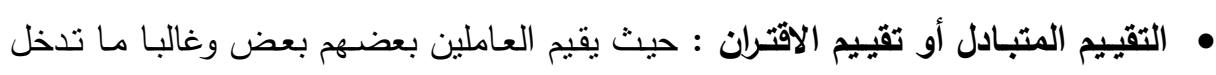

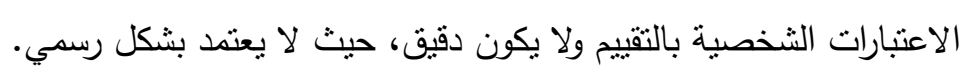

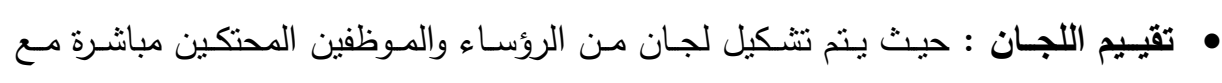

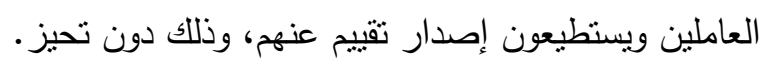
• التقييم الذاتي : حيث يقوم الثخص أوالموظف بتقييم أدائه وهذه الطريقة تخلق الثعور بالمسؤولية لتحسين الأداء. • قييم خبراء إدارة الموارد البشرية : حيث يستعان بهم لما لهم من الخبرة والمشورة. 


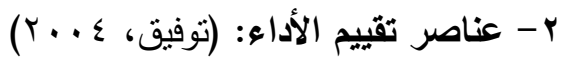

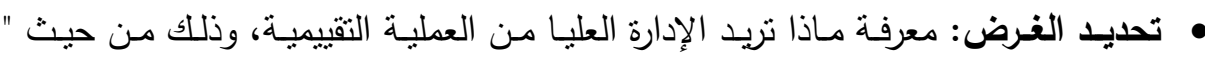

الهدف الذي تسعى له الإدارة من وراء عملية التقييم، وجمعها لهذه المعلومات والبيانات. • تحديد المسئول عن عملية التقييم: يتم اختبار احد الطرق السابقة للتقييم.

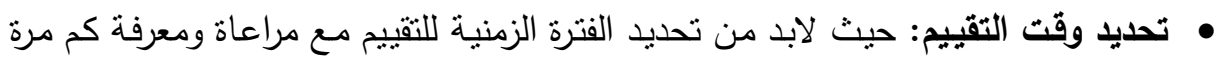
سوف ينم التقييم ومتى، حيث غالبا ما يتم مره بالسنة.

\section{لإجباءاهي التراسمة}

يتتاول هذا المبحث وصفاً لمنهج الدراسـة، وأفراد مجتمع الدراسة وعينتها، وكذلك أداة الدراسة المستخدمة، كما يتضمن وصفا للإجراءات التي قام بها الباحث في تطبيق أدوات الدراسة، وطرق إعدادها، وصدقها وثباتها، وأخيراً المعالجات الإحصائية التي تم الاعنماد عليها في تحليل الدراسة لاختبار صحة الفرض الذى تقوم عليها الدراسة. أولاً: منهجية البحث: تم الاعتماد على المنهج الوصفي التحليلي، لوصف الظاهرة موضوع

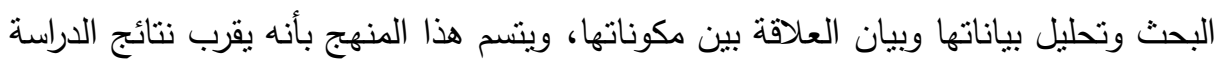
من الواقع ويمكنها من وصف الظواهر بشكل دقيق. ثانياً : مجتمع وعينة الدراسة: 1- عينة الاراسة: إن مجتمع الدراسة يساوي 9019 1 من الفئات الإدارية المختلفة للعاملين بوزارة الزراعة والاشغال العامة والموارد المائية، وبالاعتماد على جداول العينات الإحصائية

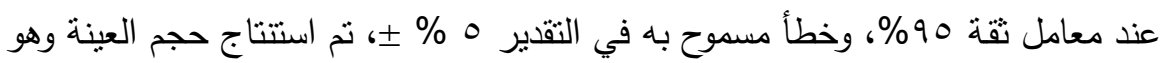

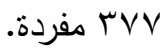

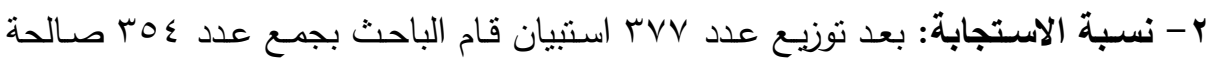
للتحليل الإحصائي وبذلك تكون نسبة الاستجابة هي ( \%، وهي نسبة استجابة جيدة جداً مقارنة بالمجتمعات المماثلة لمجتمع الدراسة. 
r- قائمة الاستقصاء: تم تصميم استمارة استقصاء والتي تضمنت مجموعة من العبارات لقياس اتجاهات أفراد عينة الدراسة تجاه متغيرات الدراسة المختلفة، وقد تضمنت الأنداء الاستمارة

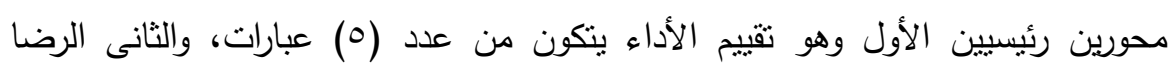
الوظيفى يتكون من عدد (ع ا) عبارة، وتم حساب الصدق والثبات لهم، ولتصميم هذه التهن

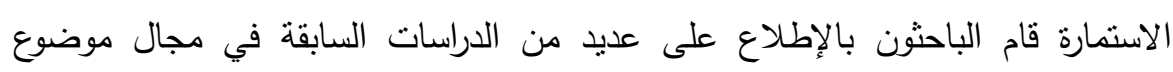

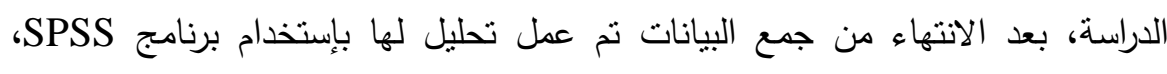
لتفريغ البيانات وجدولتها وإجراء التحليل الإحصائي المناسب لتحليل البيانات ولإختبار صحة فروض الدراسة، وتطلب ذلك تطبيق بعض أساليب الإحصاء الوصفي والإحصاء التحليلي كالآتي:

أ) الإحصاء الوصفي: تم الاعتماد على الإحصاء الوصفي وكل من الوسط الحسابي

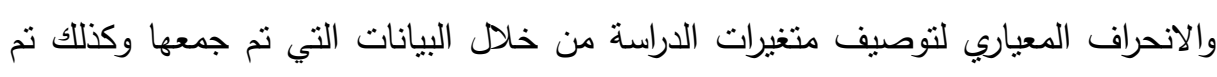

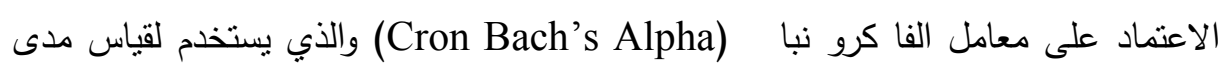
الصدق والثبات للأسئلة الموجودة في الاستقصاء، وكذلك التأكد من مدى أهمية هذه الأسئلة بالإضافة إلى استخدام معامل إرتباط بيرسون وذلك لقياس ثبات أداة الدراسة.

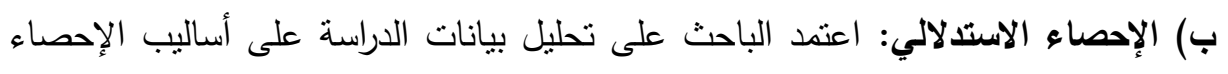
التحليلي للتحقق من مدى صحة الفرض، حيث نم استخدام تحليل الانحدار الخطي البسيط، هو اسلوب احصائي يستخدم لاختبار أنز متغير مستقل واحد على متغير تابع واحد بطريقة

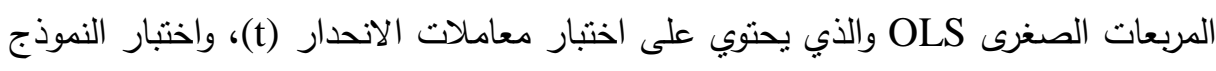
الكلي (F) وبعض اختبارات التحقق من افتراضات المربعات الصغرى.

\section{ثالثاً: التحليل الاحصائي لنتائج الاراسة الميدانية:}

1- معامل الصدق والثبات (ألفا كرونباخ): نم حساب معاملي الصدق والثبات لأسئلة الاستقصاء في عينة الدراسة ، وذلك لبحث مدى ثبات (Cronbach Alpha)

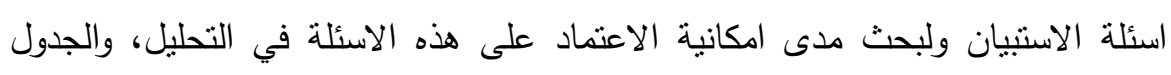
التإلى يوضح قيم معاملي الصدق والثبات لدحورى الاسنتيان. 
جدول رقم(1): معامات الصدق والثبات

\begin{tabular}{|c|c|c|c|c|}
\hline معامل الثبات & ألفاكرونباخ الصدق & عدد العبارات & اسم المحور & p \\
\hline., 909 & $\cdot, 9 Y 1$ & 0 & تقييم الأداء & 1 \\
\hline$\cdot, 9 \vee 9$ &., 97 & $1 \varepsilon$ & الرضا الوظيفي & $r$ \\
\hline
\end{tabular}

من الجدول السابق يتضح أن معاملات الصدق والثبات مقبولة لأسئلة الاستبيان ككل، لان جميع قيم معاملى الصدق والثبات تجاوزت (0, · ) في عينة الدراسة، وبالتالي يمكن القول

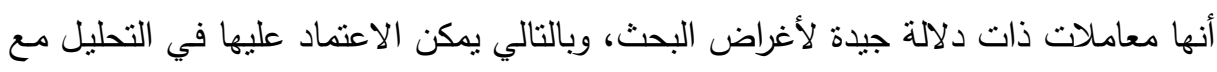
عدم استبعاد اي عنصر من عناصر المتغيرات محل الدراسة.

\section{النمانئم}

رابعاً: الإحصاء الوصفي لنتائج الدراسـة الميدانيةة: فيما يلي عرض لنتائج الحصاء الوصفي في هذه الدراسـة حيث تم الاعتمـاد على الوسـط الحسـابي المـرجح ، والانحـراف المعياري، وكذللك الاهمية النسبية والتي تعد انعكاسـا لقيمة المنوسط المرجح في صورة نسبة

القســم الأول: تقيـيم الأداء: تتـاول الباحث مـن خـلال الدراسـة الميدانيـة لتقدير تقيـيم الأداء

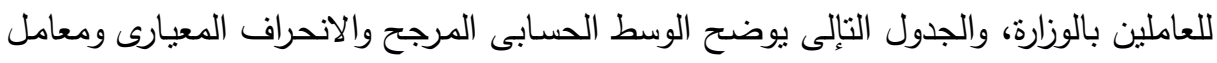
الاختلاف والنسبة المئوية لدرجة الموافقة والترتيب الجديد لكل عبارة من العبارات الخمس لتقيطيم

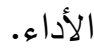


جدول رقم (ץ): المقاييس الإحصائية لوصف الجمل التى تفسر تقييم الأداء

\begin{tabular}{|c|c|c|c|c|c|c|}
\hline الترتيب & 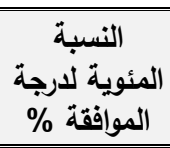 & $\begin{array}{l}\text { الاختلاف } \\
\text { \% معلم }\end{array}$ & المعياري & الصسابي & 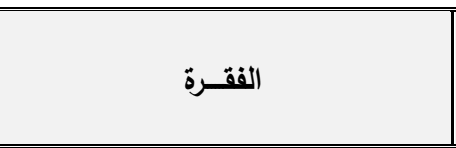 & م \\
\hline 1 & or, 10 & $\varepsilon r, q$ & $1,1 \leq 0$ & $r, 7)$ & 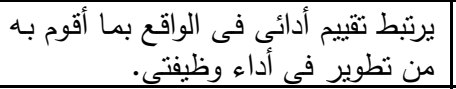 & 1 \\
\hline r & $\{0, \wedge \wedge$ & or, MA & I,rir & $r$, rq & 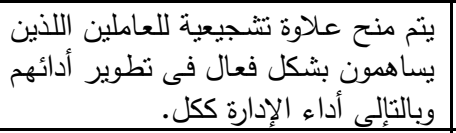 & 0 \\
\hline$r$ & $\{\leqslant, \wedge \uparrow$ & «^ & $1, \cdot v V$ & $r, r \leq$ & 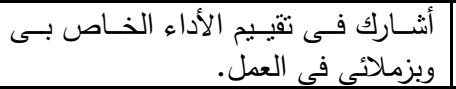 & $r$ \\
\hline$\varepsilon$ & $\varepsilon \leqslant, 7 \pi$ & $0 \leqslant, 0 \leqslant$ & $1, r \mid V$ & $r, r T$ & 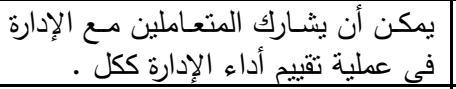 & $r$ \\
\hline$\circ$ & $\varepsilon r, T V$ & $0 \cdot, V Y$ & $1,1 \cdot 1$ & $r, 11$ & أنشارك فى تقييم أداء رئيسى فى العمل & $\varepsilon$ \\
\hline
\end{tabular}

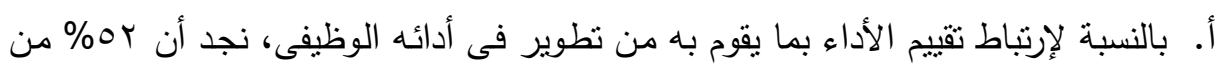

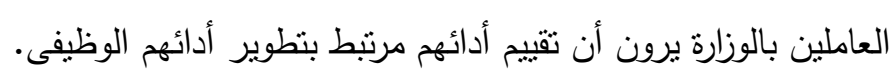

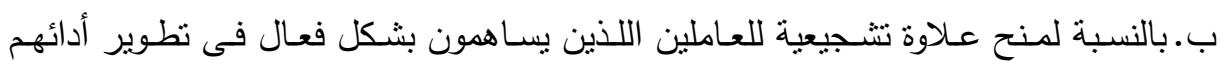

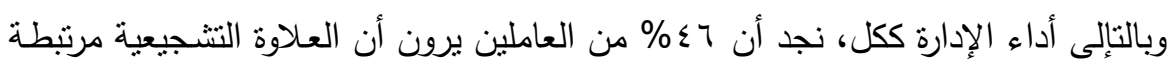

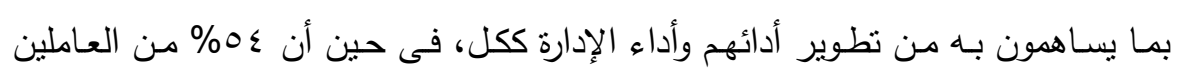
يرون غير ذلك.

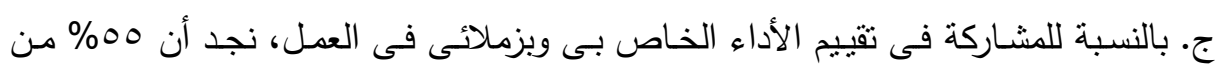

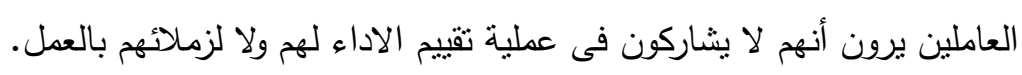

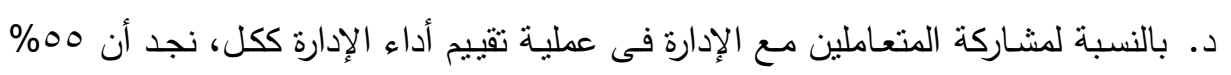
من العاملين لا يرون هناك مشاركة فى ذلك.

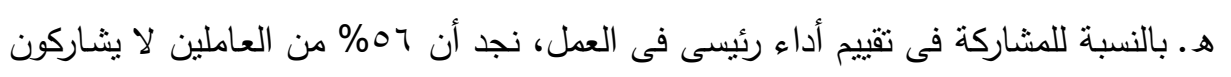
فى تقييم رئيسهم فى العمل. 
من مجموعـة العبارات السـابقة والخاصـة بتقيم الأداء، نجد أن هنـاك رضـا عن تقيهم

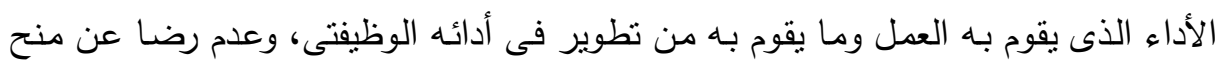

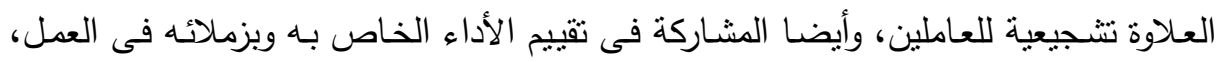

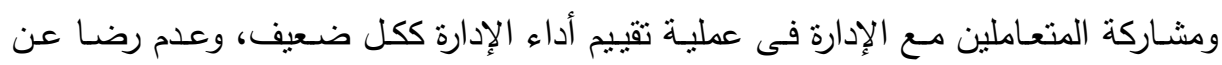
المشاركة فى تقييم أداء رئيسهم فى العمل. القسم الثانى: الرضا الوظيفى: تتاول الباحث من خلال الدراسة الميدانية لتقدير الرضا لوظئى لونيفى

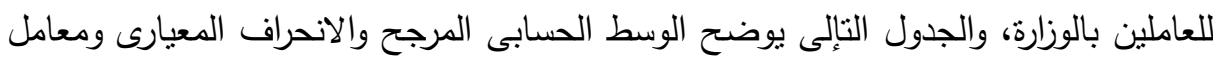

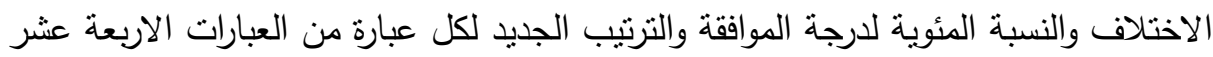

للرضا الوظيفى. جدول رقم (ب): المقاييس الإحصائية لوصف الجمل التى تقسر الرضا الوظيفى

\begin{tabular}{|c|c|c|c|c|c|c|}
\hline الترتيب & 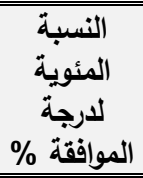 & $\begin{array}{c}\text { الاختلاف معامل } \\
\text { \% }\end{array}$ & الانحراف & المسابط المرجي & الفقـــرة & b \\
\hline 1 & $09, \leqslant 9$ & $\varepsilon \vee, \wedge \varepsilon$ & $1, \Sigma Y T$ & r, $9 V$ & العلاقة مع زملاء العمل. & $\varepsilon$ \\
\hline r & or, $\cdot 9$ & $\leqslant 7, \leqslant 0$ & $1, r_{1}$ & $r, T$ & 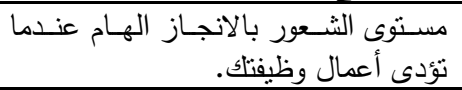 & $\mathrm{V}$ \\
\hline r & $01, \leqslant 1$ & $\leqslant 9,00$ & $1, Y \vee \varepsilon$ & T,OV & 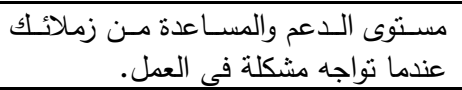 & $\Lambda$ \\
\hline$\varepsilon$ & $\leq q, \wedge r$ & $\leqslant \wedge,\rceil \leqslant$ & I,Y & $r, \leqslant q$ & تحصل علئوى التقدير والمعاملـة العادلــة التـى & 0 \\
\hline 0 & $\varepsilon q, r \wedge$ & $\varepsilon 0, \varepsilon \Gamma$ & $1,1 K r$ & $r, \Sigma V$ & 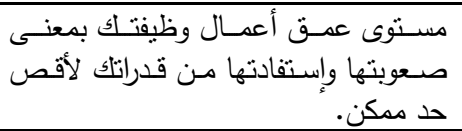 & IT \\
\hline 7 & $\sum \wedge, \vee \uparrow$ & $\leqslant \Lambda, \cdot 9$ & $1, I V Y$ & $r, \Sigma \varepsilon$ & بسبب مزاولة أعمال وظيفتلكي. مهاراتك وخبراتك & $r$ \\
\hline V & $\varepsilon \wedge, \cdot \Lambda$ & $\left.\sum \Lambda, \cdot\right\urcorner$ & 1,100 & $r, \varepsilon$ & مستـوى المســاعدة والتوجيـه مـن رئيســـ & 9 \\
\hline$\wedge$ & $\leq V, \leqslant\rceil$ & $\{\wedge, 0\rceil$ & $1,10 r$ & T,rV & 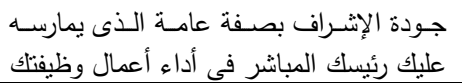 & Ir \\
\hline 9 & $\leqslant 0, \vee\urcorner$ & 00,90 & $1, r \wedge$ & $r, r q$ & 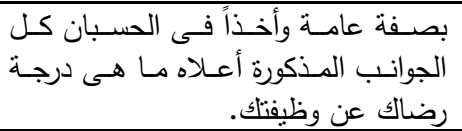 & $1 \varepsilon$ \\
\hline
\end{tabular}

المجلد الثامن والأربعون، الجزء الأول، ديسمبر 19. r 


\begin{tabular}{|c|c|c|c|c|c|c|}
\hline الترتيب & 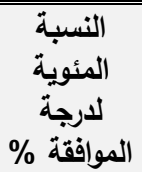 & $\begin{array}{c}\text { الاختلاف معامل } \\
\text { \% }\end{array}$ & 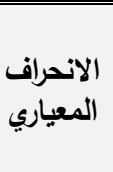 & المسابط المبط & القق_ــرة & م \\
\hline 1. & $\varepsilon r, T V$ & $01, \leqslant Y$ & אזו, & $r, 1 \wedge$ & 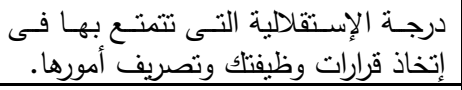 & 11 \\
\hline 11 & $\varepsilon r, T$ & or,,$T$ & $1,1.9$ & $r, I r$ & 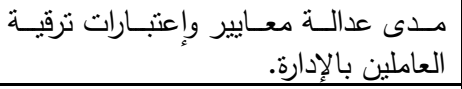 & 7 \\
\hline ir & $\varepsilon r, \varepsilon r$ & $\leqslant 9,10$ & $1, \cdot \leq r$ & $r, I r$ & 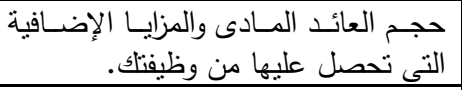 & 1 \\
\hline$\pi$ & $\varepsilon r, r r$ & or, 9 & 1,119 & $r, I r$ & 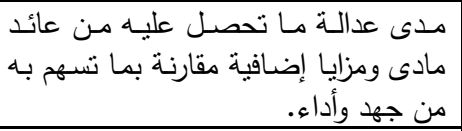 & 1. \\
\hline $1 \varepsilon$ & r^,०१ & $07, \cdot 1$ & $1, \cdot \wedge r$ & 1,94 & بـالإدارة. كفايــة فـرص الترقيـــة المتاحـــة & $r$ \\
\hline
\end{tabular}

$$
\text { بتضح من الجدول السابق أن: }
$$

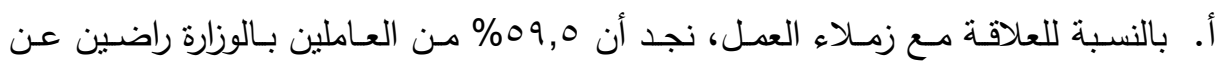

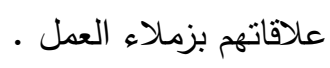

ب. بالنسبة لمستوى الثعور بالانجاز الهام عندما تؤدى أعمال وظيفتك، نجد أن بor\% من

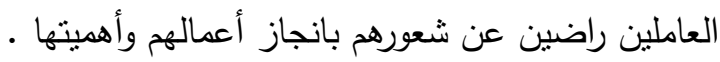

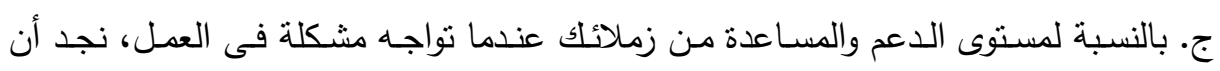
1\% من العاملين، النصف تقريبا راضين على مستوى الدعم والمساعد بين الزملاء.

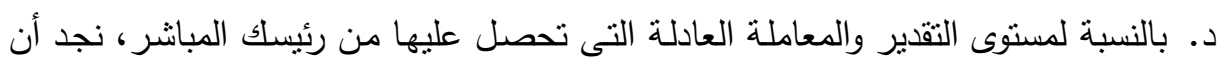

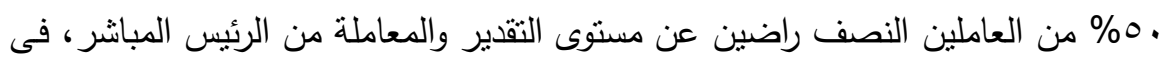

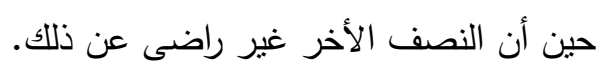

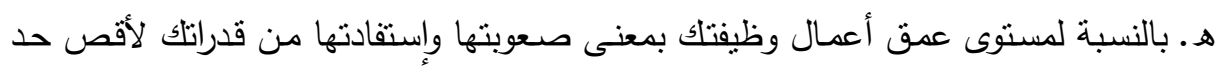

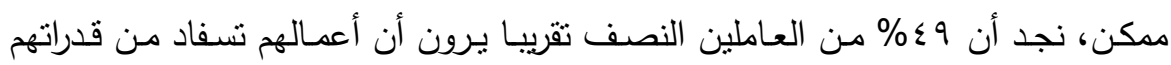

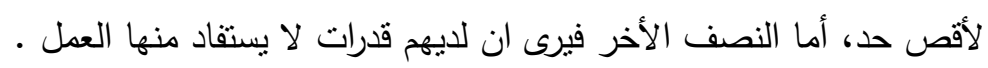

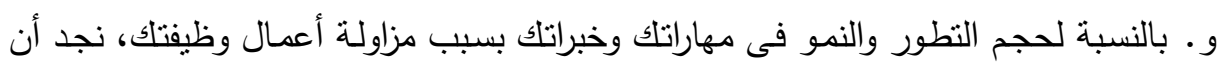

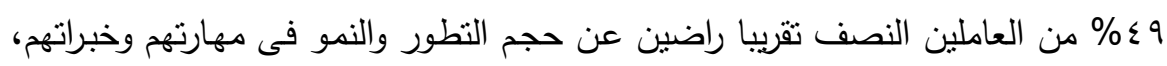
فى حين أن النصف الأخر غير راضى عن تطور ونمو مهارته وخبراته .

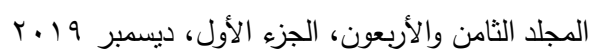


ز • بالنسبة لمستوى المساعدة والتوجيه من رئيسك المباشر ، نجد أن بo\% من العاملين غير راضين عن ذللك وقد يرجع ذللك إلى جودة الإثشراف بصفة عامة. ح. بالنسبة لجودة الإثراف بصفة عامـة الذى يمارسه عليك رئيسك المباشر فى أداء أعمال

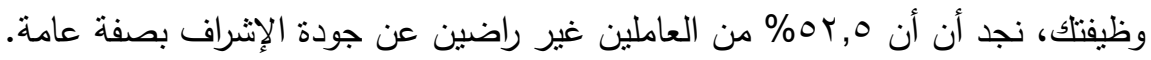

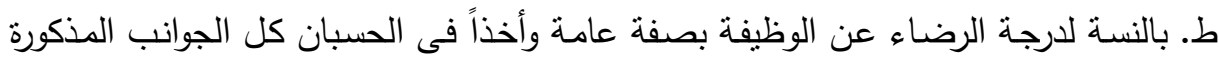

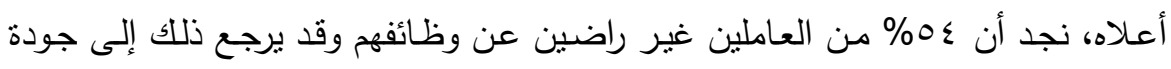

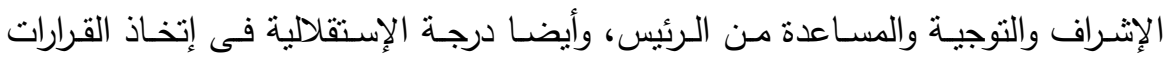

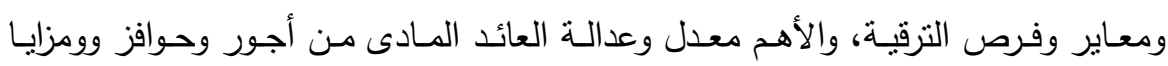
إضافية. ي. بالنسبة لدرجة الإستقلالية التى تتمتع بها فى إتخاذ قرارات وظيفتلك وتصريف أمورها، نجد أن r, ז0\% من العاملين ليس لديهم هذه الدرجة من الاستقلالية.

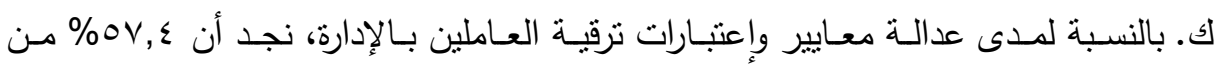
العاملين غير راضين عن هذه المعاير والاعتبارات الخاصة بترقيتهم.

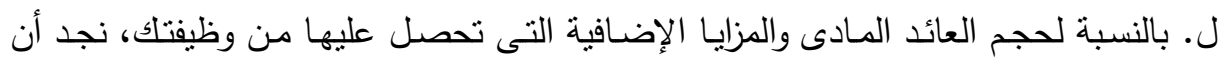

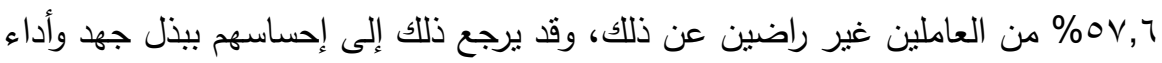

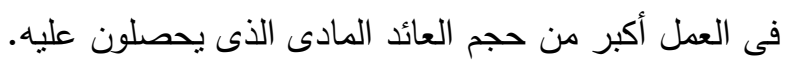

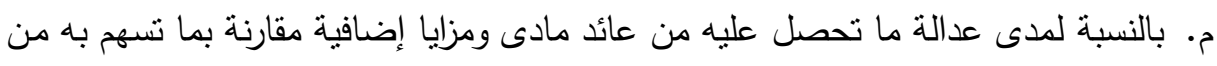

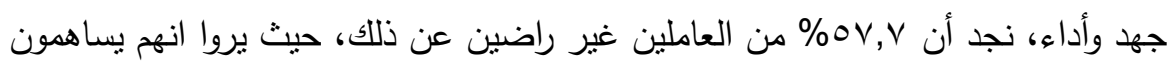

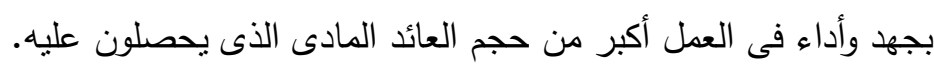

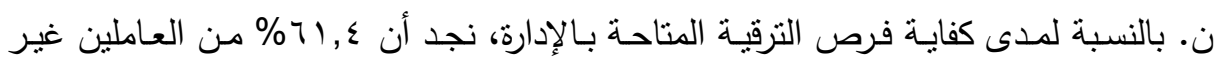

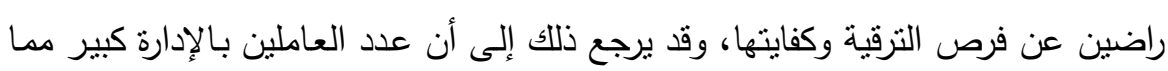
يقلل فرص الترقية بالنسبة لهم. 
من مجموعة العبارات السابقة والتى تقيس الرضـا الوظيفى، نجد أن العاملين راضين

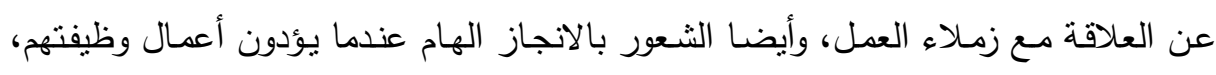

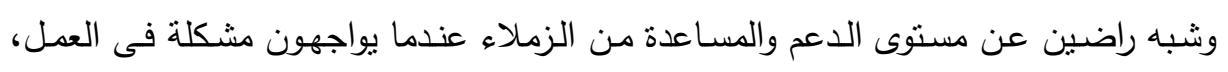

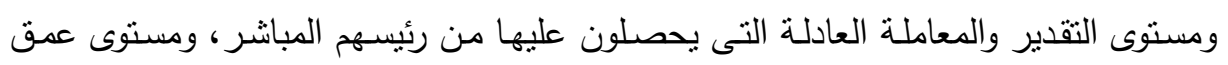

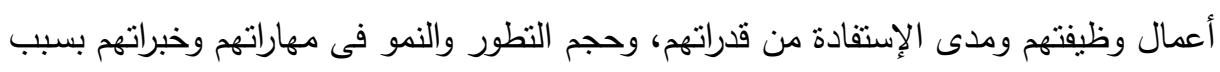

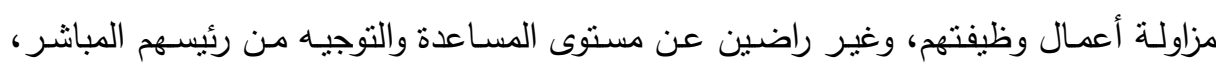

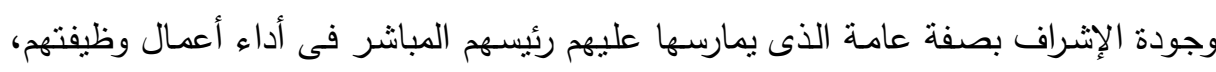
ودرجة الإستقلالية التى يتمتعون بها فى إتخاذ قرارات وظيفتهم وتصريف أمورها، ومدى عدالة التهاتيا

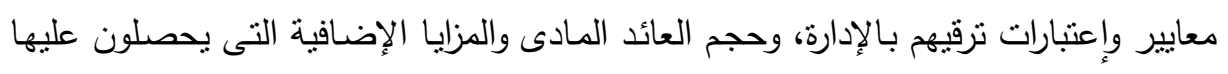

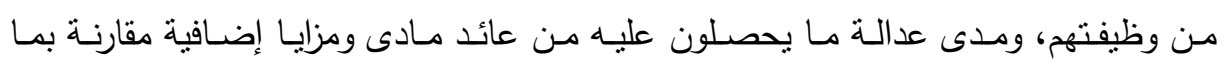
يسهون به من جهد وأداء، وأخيرا مدى كفاية فرص الترقية المتاحة بالإدارة.

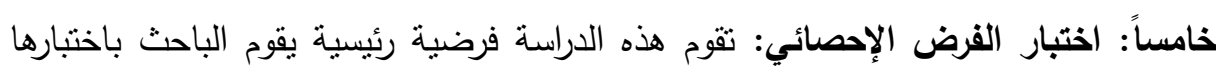
النحو التالي: - n امسنا: ينص الفرض والذي نم صياغته في صورة فرض العدم على أنه " لا يوجد تأثير جوهرى

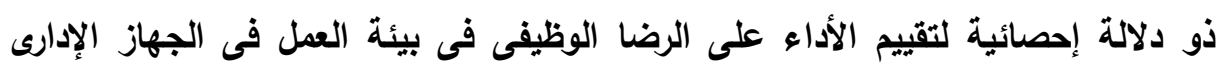
بالاولة " دولاله وحتى نتمكن من اختبار الفرض فقد نم استخدام تحليل الانحدار الخطي البسيط، وذللك

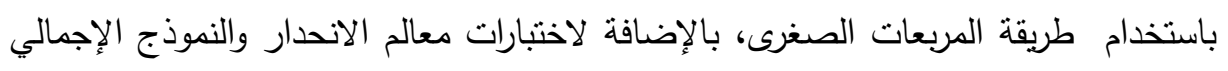
(f) (f) مع بعض اختبارات التحقق من افتراضات مقدرات المربعات الصغرى وأسفرت نتائج التحليل الإحصائي للباحث في هذا الفرض على النتائج التالية: المتغير التابع: الرضا الوظيفي 
جدول رقم (؛ ): اختبار معاملات الانحدار ونتائج الارتباط للفرض

\begin{tabular}{|c|c|c|c|c|c|c|}
\hline 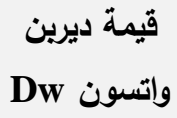 & معامل ارتباط مالإجمالي & القرار عند & مستوى & قيمة t & معامل & المستقل \\
\hline l,Vr. & r TOY & معنوي & $\cdot, \cdot$ & 17,1 & $\cdot, T Y 1$ & تقييم الأداء \\
\hline
\end{tabular}

\begin{tabular}{|c|c|c|c|c|c|c|}
\hline & & \multicolumn{5}{|c|}{ جدول رقم (•): تحليل التباين ANOVA للفرض الفرعي } \\
\hline النسبرة الغير & التعديد معامل r2 & $\begin{array}{l}\text { القرار ع=0.05 } \\
\alpha=05\end{array}$ & مستوي & F قيمة F & الدرجاتة & الاختلاد \\
\hline$\%$ ov, o & $\% \leq r, 0$ & ري & $\cdot$ & $r \circ 9,7$ & $\begin{array}{c}1 \\
\text { ror }\end{array}$ & الالتحدار \\
\hline
\end{tabular}

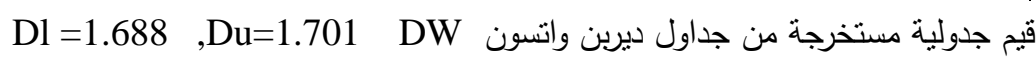

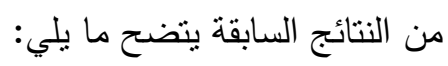
أ- من جدول اختبار معاملات الانحدار ونتائج الارتباط:

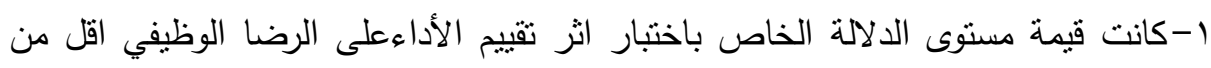

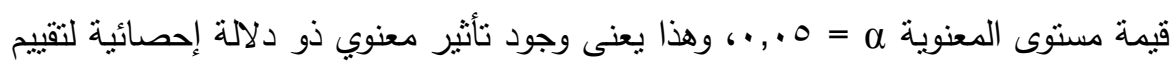
الأداء وذلك على الرضا الوظيفي. r-كانت إثارة كل من معامل ارتباط بيرسون وكذلك معامل الانحدار الوارد إثارة موجبة وهذا

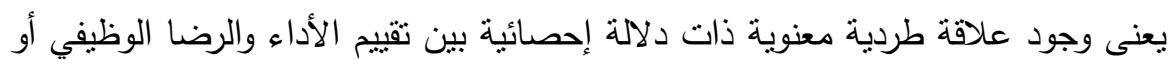

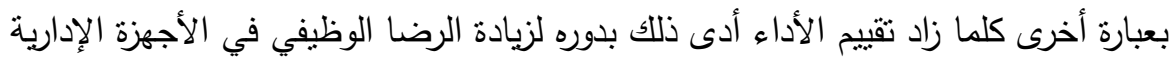

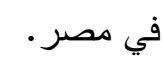

\section{ب- من جدول تحليل التباين ANOVA :}

ا-كانت قيمة مسنوي الدلالة لاختبار معنوية النموذج الإجمالي (F) اقل من قيمة مستوى

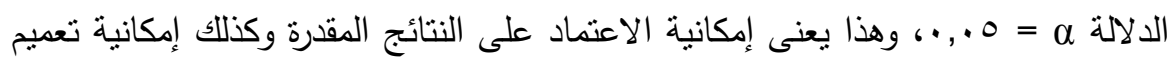
نتائج العينة على مجتمع الدراسة. 


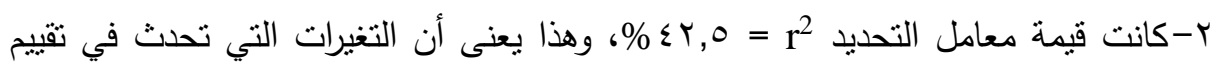

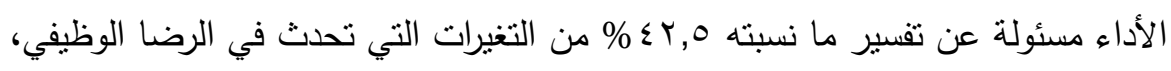

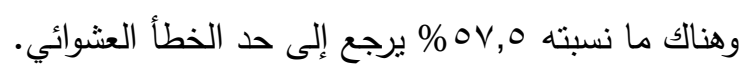

$$
\text { ج- التحقق من افتراضات المريعات الصغرى: }
$$

- لاختبار مشكلة الارتباط الذاتي بين بواقي الانحدار، كانت قيمة إحصائية ديربن واتسون المحسوبة Dw = • • Pr, ا، وبالنظر للقيم الجدولية يتضح أن القيمة المحسوبة نقع بين القيمنين الجدوليتين (Du, 4- Du)، وهذا يعنى عدم وجود تام لمشكلة الارتباط الذاتي.

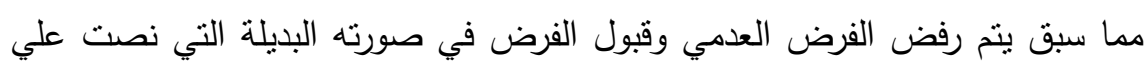

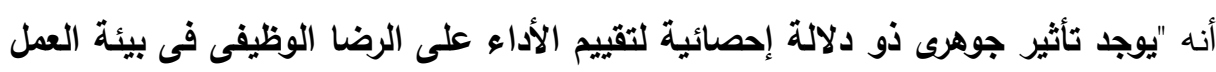

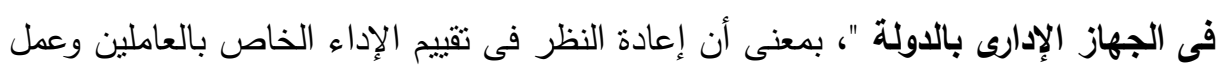

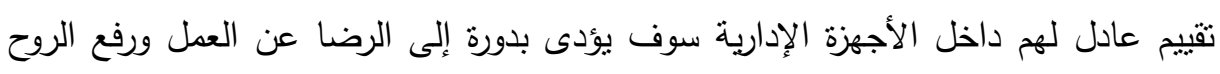
المعنوية لهم مما يؤدى إلى الرضا الوظيفى. لإدمان.

\section{المتحائج والميوكياهت}

$$
\text { : النتائجج }
$$

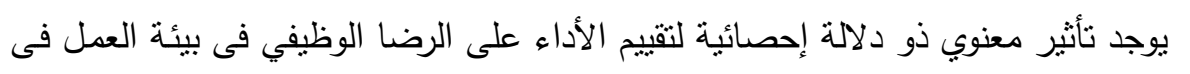

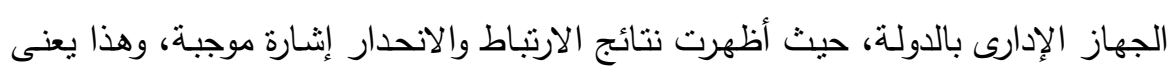

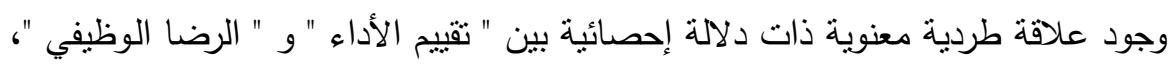

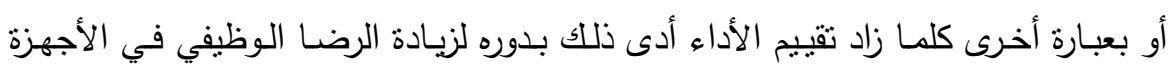

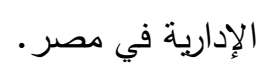

• وجود ملامح الإستياء والتذمر ظاهرة على وجوه أغلبية العمال الذين عبروا عن عدم وجود

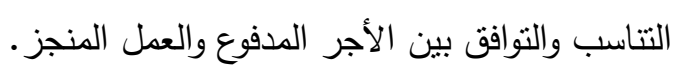

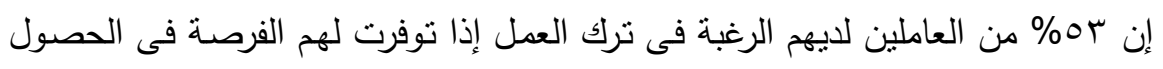

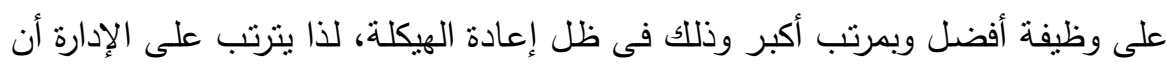

تلعب دورا كبيرا وتعيد النظر لإعادة الإستقرار وخلق التوازن لتحقيق الأداء المطلوب. 


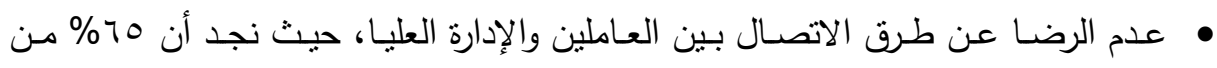

العاملين يتمنون أن يحدث تغيير إيجابى فى طرق الاتصال بين العاملين والإدارة العليا.

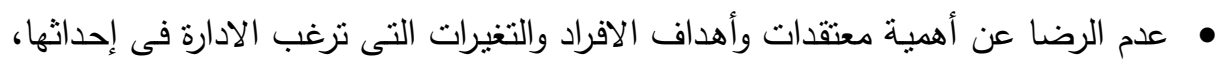
حيث نجد أن آT\% من العاملين يتمنون أن تكون هناك أهمية لمعتقداتهم وأهدافهم بالنسبة الهية

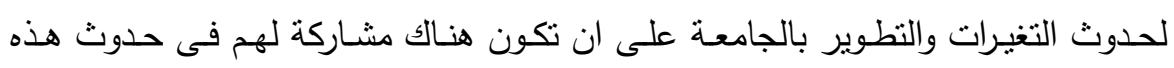
التغييرات.

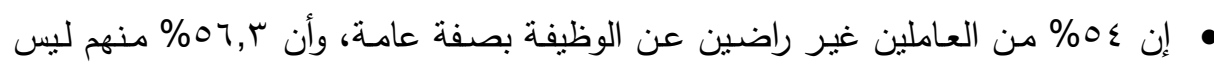

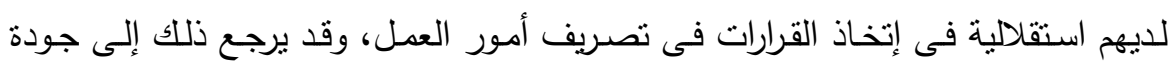

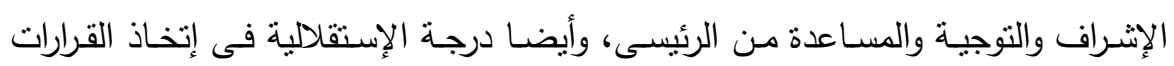

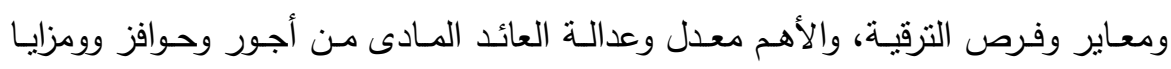
إضافية.

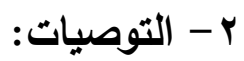

تدعيم الاتصالات المباثرة وغير المباشرة بين القيادات الإدارية وبين مختلف مستويات

التتظيم ليتسنى للقائد الإداري التأثير الإيجابي على العاملين بما يخدم العملية الإدارية. استخدام التدريب والتوجيه وإتاحة الفرصة للموظفين بالمشاركة في البرامج المختلفة لتتمية التئية

مهاراتهم، بما يهيئ مقومات أداء فاعل، وتوجيه جهودهم لتتعكس على مستوى أدائهم .

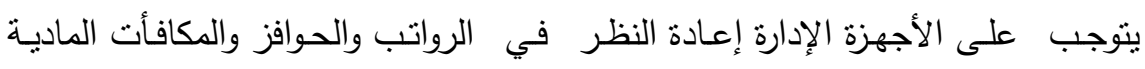
للموظفين بحيث تكون أكثر ملائمة مع متطلبات الحياة المعيشية لهم، وذلك من شأدأنه

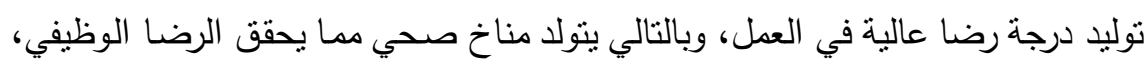
وذللك من خلال البحث في دوافع الموظفين كي يقدم لهم التحفيز المقابل والمناسب.

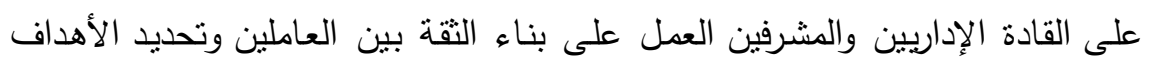

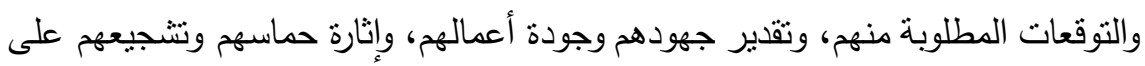
روح المبادرة والإبداع والإبتكار والإحساس بالمسئولية وتتجيع الأداء الناجح والتحفيز

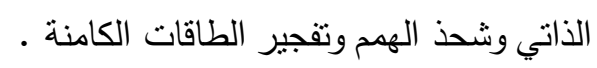




\section{المرالئ}

اسعد، محسن اسعد، ورسلان، نبيل اسماعيل، ع 91 ا، الرضا الوظيفي للقوي البشرية العاملة

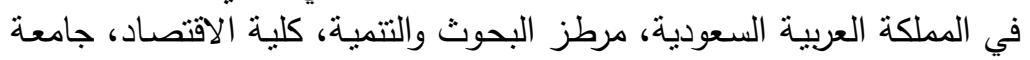

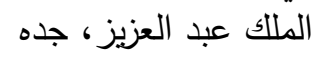

أوسم، عملية تقييم الأداء، 9 . . r، منتدى علوم الاقتصاد والإدارة في الإمارات جده

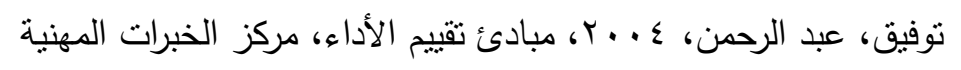

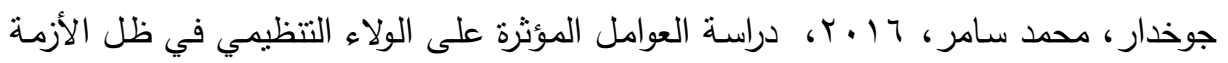

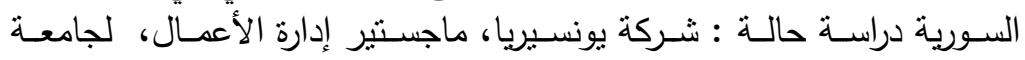

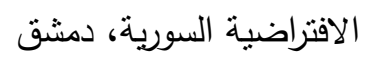

حسين، حريم، و99 1، السلوك التنظيمي : سلوك الأفراد في المنظمات، دار زهران للنشر ،

$$
\text { عمان }
$$

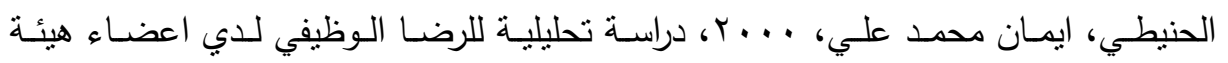

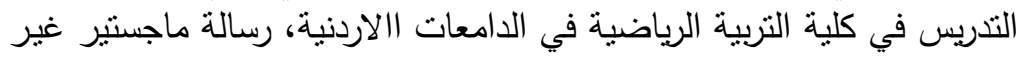

منشورة، كلية الدراسات العليا، الجامعة الاردنية

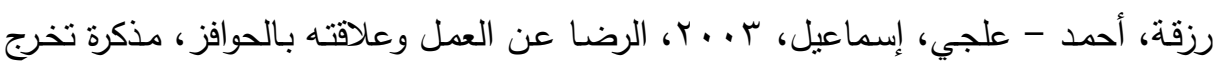
لنيل شُهادة ليسانس، المركز الجامعي بالمدية

سلطان، محمد سعيد، السلوك التتظيمي، قسم إدارة الأعمال، كلية التجارة، جامعة الإسكندرية لبهاية r... r

شوقي، طريف، س991 1، السلوك القيادي وفاعلية الادارة، مكتبة غريب، القاهرة عاشور ، أحمد صقر، 910 19، إدارة القوى العاملة، الإسكندرية، دار المعرفة الجامعية

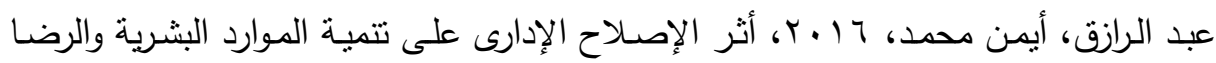

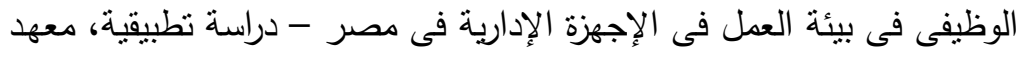

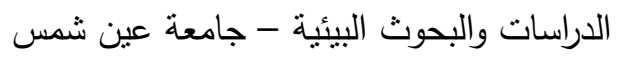

العتيبي، ب9919، علاقة بعض المتغيرات الثخصية بالرضـا الوظيفي، مجلة الادارة العامـة، معهد الادارة العامة، الرياض لعضرات

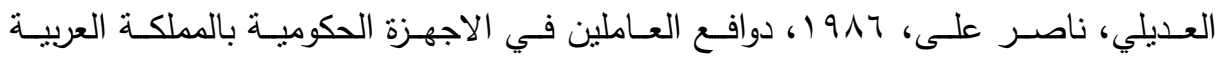
السعودية، معهد الادارة العامة - الرياض العاض الإل 


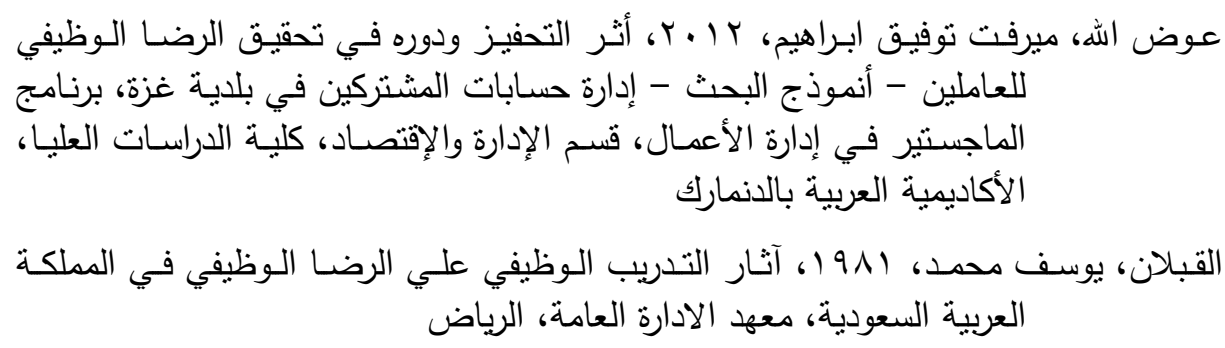

AlZalabani, Abdulmonem1, 2014, Modi, Rajesh S.2 - Impact of Human Resources Management Practice and Perceived Organizational Support on Job Satisfaction: Evidence from Yanbu Industrial City, KSA. - IUP Journal of Organizational Behavior. Vol. 13 Issue 3.

Andreassi, Jeanine Karin - Lawter, Leanna - Brockerhoff, Martin Rutigliano, Peter J. 2014,- Cultural impact of human resource practices on job satisfactionA global study across 48 countries - Cross Cultural Management. Vol. 21 Issue 1.

González Santa Cruz, Francisco , López-Guzmán, Tomás, Sánchez Cañizares, Sandra María, 2014,- Job satisfaction and organizational commitment in human resources in the hotel sector of Cordoba (Spain): Influence of the type of contract and working day - Intangible Capital. Vol. 10 Issue 1.

Gould-williams, julian s. - bottomley, paul - redman, tom - snape, ed bishop, david j. 2014, - limpanitgul, thanawut - mostafa, ahmed mohammed sayed - Civic Duty And Employee Outcomes: Do High Commitment Human Resource Practices And Work Overload Matter? - Public Administration. Vol. 92 Issue 4.

Mostafa, Ahmed Mohammed Sayed - Gould-Williams, Julian Seymour - 2014, Testing the mediation effect of person-organization fit on the relationship between high performance HR practices and employee outcomes in the Egyptian public sector - International Journal of Human Resource Management. Vol. 25 Issue 2.

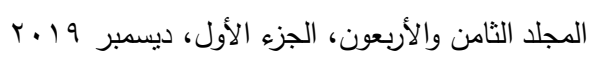


طارق محمد عبد العزيز حمزة وآخرون

\title{
THE IMPACT OF PERFORMANCE EVALUATION ON THE JOB SATISFACTION OF WORKERS IN THE WORK ENVIRONMENT OF THE STATE ADMINISTRATIVE APPARATUS
}

\author{
Tarek M. A. Hamza ${ }^{(1)}$; Nader A. Fanous ${ }^{(2)}$ \\ and Mahmoud A. M. Amin (2) \\ 1) Armed Forces 2) Faculty of Commerce, Ain Shams University
}

\begin{abstract}
Job satisfaction is one of the characteristics that the organization usually uses as an alternative to performance, and seeking to develop relations between the working people and the organization to ensure the continuity of the workforce. It also works to develop the creative behavior of employees and search for motivation to adapt the effort and activate performance to achieve full functional satisfaction and development Based on the importance of job satisfaction, this research deals with the study and analysis of the impact of performance evaluation on the job satisfaction of workers in organizational effectiveness by showing differences in the degree of response of employees, where the research aims to achieve a key objective It is a measure of the impact of performance evaluation on job satisfaction in the work environment in the administrative apparatus of the State, using the descriptive and analytical method, has been used a questionnaire questionnaire, and the sample of the study 354, and through the achievement of a set of sub-objectives, namely: Job Satisfaction Requirements, Recognition of Employee Satisfaction with Performance Appraisals, Recognition of the Relationship between Performance Appraisal and Job Satisfaction of Employees, Measuring the Impact of Performance Appraisal on Job Satisfaction). Environment Work in the administrative system in the country, where the results of correlation and regression showed a positive signal, and this means a significant
\end{abstract}

$$
\text { المجلد الثامن والأربعون، الجزء الأول، ديسمبر } 19 \text { ـr }
$$


positive correlation statistically significant between "performance evaluation" and "job satisfaction", or in other words the greater the performance evaluation led to an increase in job satisfaction in the administrative system The study recommended to strengthen direct and indirect contacts between administrative leaders and between different levels of organization so that the administrative leader can positively influence the workers to serve the administrative process, and the use of training and guidance and the opportunity for employees to participate in various programs Understand their skills, which create the elements of effective performance, and direct their efforts to reflect on their level of performance.

Key words: ( job satisfaction - performance evaluation - the administrative apparatus of the state). 